This item was submitted to Loughborough's Research Repository by the author.

Items in Figshare are protected by copyright, with all rights reserved, unless otherwise indicated.

\title{
Application of flamelet/progress-variable approach to the large eddy simulation of a turbulent jet flame of pulverized coals
}

PLEASE CITE THE PUBLISHED VERSION

https://doi.org/10.1016/j.apt.2020.09.005

\section{PUBLISHER}

Elsevier and The Society of Powder Technology Japan

\section{VERSION}

AM (Accepted Manuscript)

\section{PUBLISHER STATEMENT}

This paper was accepted for publication in the journal Advanced Powder Technology and the definitive published version is available at https://doi.org/10.1016/j.apt.2020.09.005.

\section{LICENCE}

CC BY-NC-ND 4.0

\section{REPOSITORY RECORD}

Akaotsu, Shota, Yohsuke Matsushita, Hideyuki Aoki, and Weeratunge Malalasekera. 2020. "Application of Flamelet/progress-variable Approach to the Large Eddy Simulation of a Turbulent Jet Flame of Pulverized Coals". Loughborough University. https://hdl.handle.net/2134/13325678.v1. 
Application of flamelet/progress-variable approach to the large eddy simulation of a turbulent jet flame of pulverized coals

\section{Authors:}

Shota Akaotsu ${ }^{\mathrm{a}}$, Yohsuke Matsushita ${ }^{\mathrm{a}}$, Hideyuki Aoki ${ }^{\mathrm{a}}$, Weeratunge Malalasekera ${ }^{\mathrm{b}}$

Affiliation:

${ }^{a}$ Department of Chemical Engineering, Graduate School of Engineering, Tohoku University, 6-6-07 Aoba, Aramaki, Aoba-ku, Sendai, Miyagi 980-8579, Japan

b School of Mechanical, Electrical and Manufacturing Engineering, Loughborough University, Loughborough LE11 3TU, UK 


\section{Abstract:}

In this study, the flamelet/progress-variable (FPV) approach was applied to a large eddy simulation of a pulverized coal jet flame. The FPV approach considers the characteristics of the pulverized coal flame, e.g., non-adiabatic system and several types of fuel streams, via additional representative variables. First, the applicability of the FPV approach to a turbulent flame with pulverized coals was confirmed through a comparison of the numerical solutions and experimental data. In this study, the pure pilot case was also investigated to clarify the effects of pulverized coals on the flame. The flame structure changes significantly upon the injection of pulverized coals, and the flame index suggests the coexistence of premixed and diffusion combustion modes even in the downstream region. In particular, the combustion mode fluctuates with time in the middle region of the flame. The fuel gas released from the pulverized coals should increase in this region; therefore, the release and combustion behavior of the volatile matter must be involved in the combustion mode variation. The evaluation of the combustion modes of fuel gas in the coal flame is useful for the design and optimization of pulverized coal combustors with next-generation technologies.

\section{Keywords:}

Flamelet/progress-variable approach; pulverized coal combustion; large eddy simulation; jet flame; flame index 


\section{Introduction}

Energy-related issues directly affect the safety and security of our society. Because of the significant climate changes worldwide, environmentally friendly technologies have advanced primarily in industrialized countries. In recent years, power generation via the combustion of fossil fuels, including coals, has been explored as a primary energy resource to support the transition to a "carbon-free" society. According to the International Energy Outlook 2019, coal use increased in both industrial and electric power sectors in the countries of non-OECD Asia, excluding China [1]. Among the fossil fuels, coal has been widely used as an energy source owing to its low cost and worldwide distribution. However, $\mathrm{CO}_{2}$ emission per calorific value is larger than that from other fossil fuels; therefore, coal utilization has shown a decreasing trend in several industrial fields. Conversely, new technologies, such as coal gasification and oxy-fuel combustion, are expected to achieve highefficiency and low $\mathrm{CO}_{2}$ emission, thus initiating interest in their application in practical combustors. Because there are a minimum of a thousand chemical reactions, heat transfer, and turbulence interfere in the reaction field of pulverized coals, numerical simulations that provide detailed information are necessary to accelerate technological development.

The prediction accuracy of computational fluid dynamics (CFD) for practical devices largely depends on numerical methods of turbulence, namely, direct numerical simulation (DNS), large eddy simulation (LES), or Reynolds averaged Navier-Stokes equations (RANS). In recently conducted CFD tests for pulverized coal combustion, LES has often been used because it facilitates a favorable balance between accuracy and computational cost. However, the filtered reaction rate cannot be accurately evaluated only on the basis of the filtered temperature because a strong non-linearity with temperature is exhibited. Thus, the turbulent combustion model is typically used in the LES of reacting flow, and several models have been used in previous simulations of pulverized coal combustion.

Yamamoto et al. [2] conducted an LES of a pulverized coal combustor and investigated the prediction accuracy of coal conversion and ignition positions. They evaluated the filtered reaction rate using the Kolmogorov timescale and the difference of the species mass fractions from chemical equilibrium. Franchetti et al. [3] and Rabacal et al. [4] applied the eddy-break-up (EBU) model to the LES and concluded that the EBU model overpredicted the reaction rate of volatile matter. Muto et al. [5] investigated the effect of oxygen concentration on $\mathrm{NO}_{\mathrm{x}}$ formation in a pulverized coal combustor via LES with a scale similarity filtered reaction rate model (SSFRRM) [6]. Rieth et al. [7] and Wen et al. [8] applied a flamelet approach to the LES of pulverized coal combustion according to the method proposed by Watanabe and Yamamoto [9]. In the flamelet approach, the Favre-filtered variables can be evaluated on the basis of a presumed probability density function (PDF), and the chemical kinetics is reflected in the simulation through look-up tables. Recent CFD studies of pulverized coal combustion often use the flamelet approach (e.g., [10-12]) because of its relatively low computational cost, and the number of applications for the flamelet approach is expected to increase in the future. 
Thus, we applied the flamelet/progress-variable (FPV) approach [13] to an LES of a pulverized coal jet flame and investigated the accuracy of the simulation and reaction behaviors of pulverized coal particles. In sections 2.1-2.3, the target experiment is reviewed in detail, and the theory of gas and dispersed phase modeling is described in sections 2.4-2.6. Subsequently, the numerical method and boundary conditions are summarized in addition to the mesh quality assessment, and the accuracies and flame structures are discussed using experimental and numerical results. The target jet flame is stabilized by the pilot gas in addition to the released gas from the pulverized coals, as subsequently described. While the numerical results are presented only after the injection of pulverized coals in most previous studies, the effects of the fuel gas originating from the coal are difficult to evaluate because both fuel streams affect the simulation results. To our knowledge, this study is the first attempt to extract only the effect of pulverized coals on the flame structure and to clarify the effects through a comparison of the results before and after coal supply.

\section{Numerical simulation of a laboratory-scale piloted jet flame of pulverized coals}

\subsection{Experiment by Hwang et al. [14]}

Hwang et al. [14] developed a laboratory-scale jet burner, called the Central Research Institute of Electric Power Industry (CRIEPI) burner, capable of stabilizing an open-type pulverized coal flame and observed the flame and pulverized coal particles through various optical measurement techniques. The main burner comprises an inner pipe with a $6 \mathrm{~mm}$ inside diameter and an annular slit with a 0.5 $\mathrm{mm}$ width. Upon provision of air and $\mathrm{CH}_{4}$ separately from the inner pipe and annular slit, a $\mathrm{CH}_{4} /$ air piloted flame was formed prior to the coal supply. Subsequently, pulverized coals were supplied from the inner pipe after the $\mathrm{CH}_{4}$ /air piloted flame was stabilized above the burner. The flow rates of the pulverized coals, air, and $\mathrm{CH}_{4}$ were set to the values listed in Table 1. The $\mathrm{CH}_{4}$ flow rate was set to the minimum value required for flame stabilization. The flow rate of air listed in Table 1 corresponds to that from a compressor before the pulverized coals were mixed. The air flow rate at the exit plane of the inner pipe should increase owing to additional air sucked from a pulverized coal feeder. However, the exact flow rate, including the additional air from the coal feeder, is difficult to measure. In previous simulations, the flow rate has often been adjusted to minimize the difference between the numerical and measurement results. For example, Hashimoto et al. [15] set this flow rate to $2.07 \times 10^{-4} \mathrm{~m}^{3} / \mathrm{s}$ to reproduce the experimental particle axial velocity. 
Table 1 Experimental conditions.

\begin{tabular}{lcc}
\hline Coal type & & Newlands \\
Feed rate of coals & {$[\mathrm{kg} / \mathrm{s}]$} & $1.49 \times 10^{-4}$ \\
Flow rate of air & {$\left[\mathrm{m}^{3} / \mathrm{s}\right]$} & $1.80 \times 10^{-4}$ \\
Flow rate of $\mathrm{CH}_{4}$ & {$\left[\mathrm{~m}^{3} / \mathrm{s}\right]$} & $2.33 \times 10^{-5}$ \\
Reynolds number & {$[-]$} & 2544 \\
\hline
\end{tabular}

\subsection{Computational domain}

Figure 1 shows a schematic of a computational domain. According to previous studies $[3,11]$, the computational area was set to a $50 \times 50 \times 270 \mathrm{~mm}$ rectangular region containing the burner and was divided into five million cells. The particle diameter distribution was prepared by fitting a RosinRammler distribution function to the measurements [14] converted from number-based to volumebased values. Figure 2 shows the measured [14] and calculated PDF. According to previous studies [3, 16], seven types of particle diameters in the range of 5-61 $\mu \mathrm{m}$ were considered, and each mass fraction was evaluated by the calculated PDF. The mass fractions of all the particle diameters are listed in Table 2.

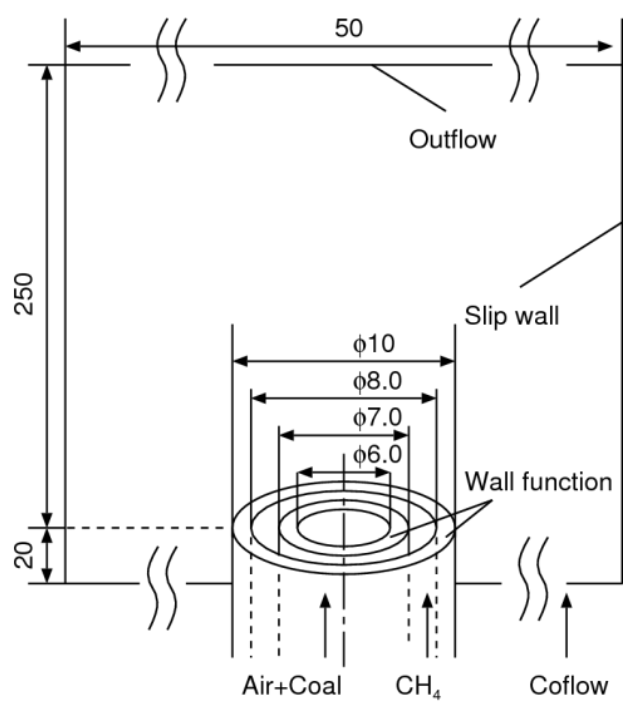

Figure 1 Computational domain. 


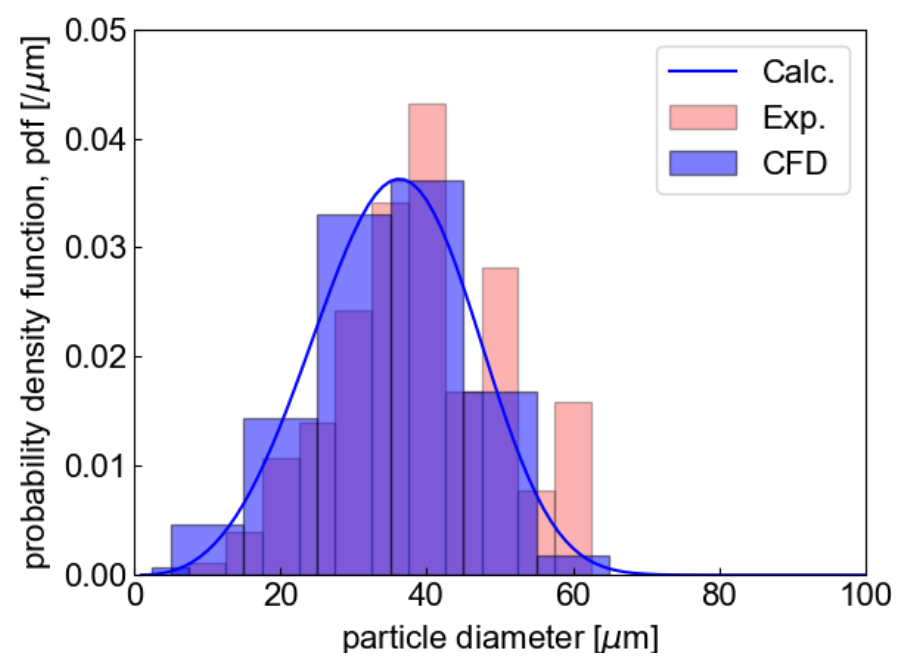

Figure 2 Measured and calculated probability density function of the particle size distribution. The violet line and blue boxes indicate the calculated PDF and the particle size distribution used in the CFD, respectively.

Table 2 Mass fraction of each particle diameter in this study.

\begin{tabular}{|c|c|}
\hline Particle diameter $[\mu \mathrm{m}]$ & Mass fraction [-] \\
\hline 5 & $\mu d_{l} \mu^{2} \quad \kappa l^{\rho: \pi r}$ \\
\hline 10 & $\lambda d \kappa^{2} \quad \kappa l^{e}{ }^{e}$ \\
\hline 20 & 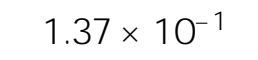 \\
\hline 30 & $\mu d \sigma v^{2} \quad \kappa l^{\rho, \eta r}$ \\
\hline 40 & $\mu d v^{2} \quad \kappa l^{g \cdot \tau}$ \\
\hline 50 & $\kappa \phi l^{2} \quad \kappa l^{g \cdot \eta \tau}$ \\
\hline 61 & $\kappa l_{l}^{2} \quad \kappa l^{e} \pi$ \\
\hline
\end{tabular}

\subsection{Summary of previous numerical studies on CRIEPI burner}

The CRIEPI burner was selected for the target flame in the International Coal and Biomass Conversion (CBC) Workshop [17] and has been investigated using experiments and simulations. Several research groups have performed an LES of this flame, and their results allow us to validate the FPV approach in this study. For example, Stein et al. [18] compared the EBU-model-derived numerical solutions among three research groups and indicated the important factors required to achieve high accuracy. Rieth et al. [19] applied a two-mixture-fraction approach of $\mathrm{CH}_{4}$ and volatile gas to the LES and investigated the effects of the devolatilization model on the solutions. Wen et al. [11] developed the multi-regime flamelet model where the two types of look-up tables were switched 
according to the local combustion mode and applied to the LES. Ahn et al. [20] used the SSFRRM and simulated the pulverized coal combustion in this domain. They investigated the momentum exchange between the dispersed and gas phases and discussed the difference between non-reacting and reacting cases.

The above LES results were compared in a workshop in 2017, and the effects of coal sub-models and reaction parameters on the predictions were discussed. Regarding the particle velocity, there is a difference between the predicted and experimental RMS values, whereas the mean values have been represented in axial and radial directions by any research group. In the axial distributions, the flamelet approach showed agreement with the measurements, while the EBU model and SSFRRM overpredicted and underpredicted the RMS values, respectively. Almost all LESs underpredicted these values at large radii. The predictions of major species also differed in the research groups. The parameter studies of the devolatilization model indicated a large impact on the species distributions, resulting in the increased importance of the devolatilization model and its reaction parameter. The numerical method and approach have not been standardized among the research groups, and the superiority was difficult to evaluate, as described in the workshop. In the last workshop session in 2019, the sensitivities of the predictions to various factors, e.g., the inflow conditions, convergence of statistics, and mesh resolution, were investigated. The mean and RMS velocities of the particles were sensitive to the perturbations added to the inflow profile. To obtain the statistically convergent RMS profiles in the downstream region, the sampling time should be more than $0.85 \mathrm{~s}$, while the relevant axial profiles could be obtained from the sampling data in $0.35 \mathrm{~s}$.

To distinguish this study from previous studies, we focused on the effect of pulverized coals on the overall combustion behaviors and explored it via a comparison of numerical solutions before and after the supply of pulverized coals. Our specific objectives were to evaluate the heat losses and combustion modes in the piloted coal flame. In pulverized coal combustion, the enthalpy decreases owing to the sensible heat of pulverized coals. To our knowledge, there has been minimal comprehensive research on the heat loss in the practical system even though it has been assessed in idealized configurations, e.g., two-dimensional counter-flow diffusion flame [21-23] and turbulent mixing layer $[24,25]$. In addition, heat loss should depend on the environmental conditions around the coal because there are several passes of heat transfer between the gas and particles. Therefore, the influence of heat loss over the presence of pulverized coals was comprehensively discussed on the basis of numerical results of pure pilot flames. Previous works $[11,26]$ have reported that premixed and diffusion combustion modes coexisted in the CRIEPI burner. As those results include the effect of pilot and volatile gas combustion, the contribution of volatiles remains unknown. The comparisons of the LES results before and after adding coal could exclude the effects of the pilot gas and could provide further useful insights for understanding the phenomena in a coal flame. 


\subsection{General governing equations}

The governing equations of fluid flow were the Favre-filtered continuity and Navier-Stokes equations under the assumption of a low-Mach number. The eddy viscosity approach was used for the modeling of sub-grid scale (SGS) turbulent momentum flux, which was evaluated via the dynamic procedure [27]. When the FPV approach is used for combustion modeling, the transport equations of representative variables, i.e., mixture fractions and progress variables, are solved instead of those of the chemical species. According to previous studies $[7,28]$, the representative variables were set to the sum of the volatile and cha off-gas mixture fractions, their ratio, SGS variance of the sum of the mixture fractions, progress variable, and enthalpy. The SGS variance of the mixture fraction was estimated using the following transport equation [29]:

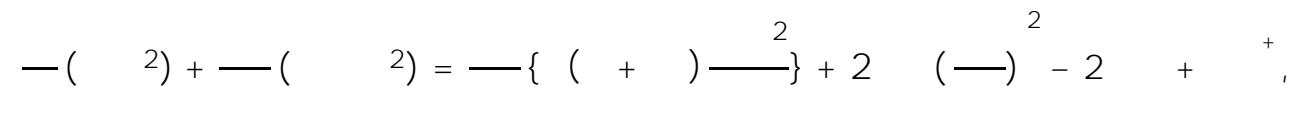

where $\mathrm{I}_{\mathrm{H}}$ and $थ$ are gas velocity and gas density, respectively; ह and ह $\mathrm{O}$ are the molecular and turbulent diffusion coefficients for SGS variance, respectively, and were estimated on the basis of the viscosity and Schmidt number under the unity Lewis number assumption. The second and fourth terms of the right-hand-side (RHS) are the source terms owing to the SGS mixture fraction and fuel release from the dispersed phase, respectively. The third term represents the influence of the SGS scalar dissipation rate and was modeled by

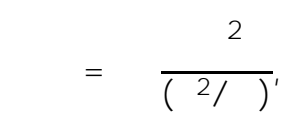

where स:: is a model parameter and was set to 8.0 according to previous spray combustion simulations $[30,31]$; स $_{\mathbf{n}}$ and 3 are the eddy kinematic viscosity and grid scale, respectively. The term यौy in Eq. (1) can be expressed as follows

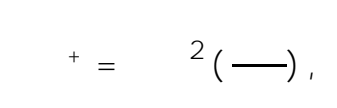

where 5 is a model constant and was set to 0.5 ; यौ혀 is a source term of the mixture fraction from the dispersed phase. This variance equation is valid for evaporating sprays only, and there is no theoretical proof that it can be applied to pulverized coal combustion. However, evaporating spray and devolatilization (or char reaction) are similar in terms of fuel release, and the source terms in the variance equations are also meaningful in pulverized coal combustion. Although there are other methods for evaluating SGS mixture fraction variances, such as scale similarity and local equilibrium assumptions, the research groups of the University of Duisburg-Essen [7, 12, 19] and Zhejiang University [8, 11, 28, 32] used the transport equations in the flamelet-LES of pulverized coal combustion. Therefore, we used the transport equation as a better evaluation method for SGS variance.

The transport equation of enthalpy was also solved to consider the heat exchange between the gas and coals. Radiative heat transfer was evaluated using the P1 approximation method [33, 34]. The 
effects of the dispersed phase on the gas phase were considered through the particle-source-in cell, (PSI-CELL) model [35]. The details of the source terms are described in our previous work [23].

\subsection{Dispersed-phase modeling}

\subsubsection{Particle mass balance}

The dispersed phase was calculated as per the Lagrangian approach. The mass of pulverized coal decreases by a devolatilization and char reaction as follows:

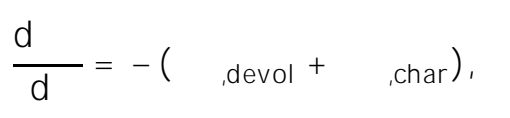

where s. $_{\Omega}$, ड़ीभy devolatilization, respectively. Under the assumption that the coal particle is composed of volatile matter, char, and ash, the total particle mass was evaluated as the sum of the aforementioned components. The initial amount of each component was obtained from a proximate analysis [14]. The Q-factor, which reflects the increase of the releasable amount of volatile matter owing to rapid heating, was set to 1.62 for all the particle diameters.

The devolatilization rate was evaluated using a classical single first-order reaction model [36]. The model equation is as follows:

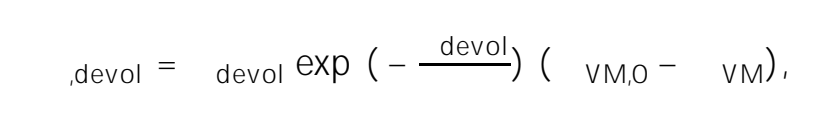

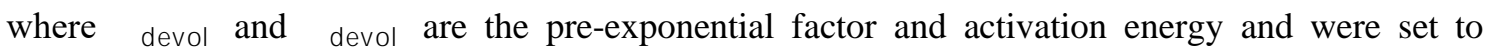

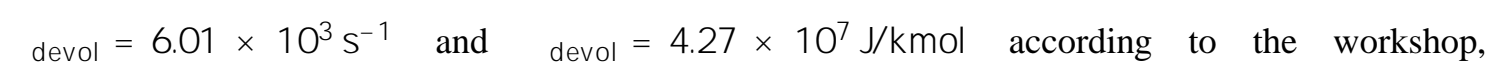

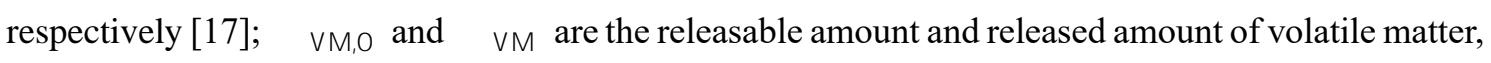
respectively. The swelling during pyrolysis was ignored in this study. For the char reaction, partial oxidation of carbon was considered. The char combustion depends on the mass transfer process of the oxidants in and around the particle as well as the chemical reaction rate of char. In this study, only the oxidant diffusion rate around the particle was considered in addition to the char chemical reaction rate. When the reaction model based on the external surface area [37] was used, the overall char combustion rate is given by

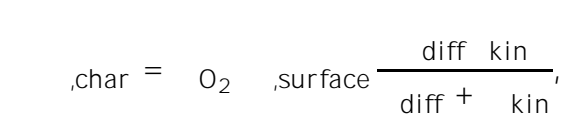

where या:, 3 , 3 , and

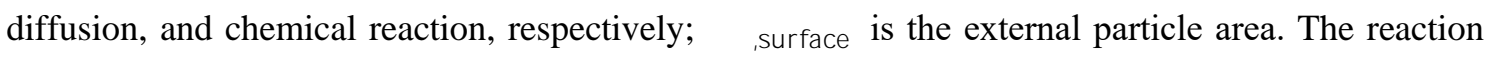
rate coefficient of the chemical reaction was evaluated using 


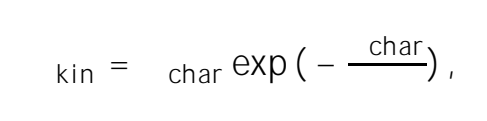

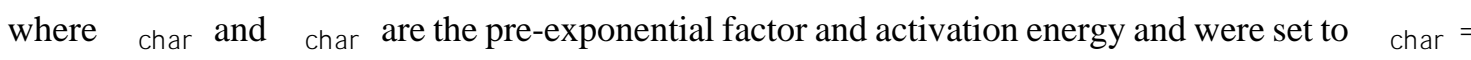

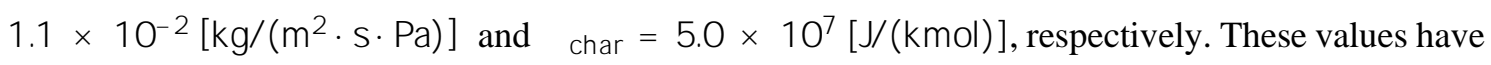
been used in previous studies $[3,18,28]$. The rate coefficient of oxygen diffusion can be calculated from the equation by Field [38]:

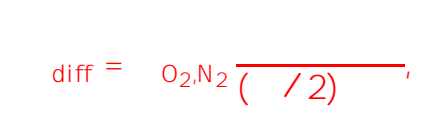

where $\breve{\Gamma}_{\theta}, t_{0^{\circ}}$ and. are the mean temperature of the gas in the boundary layer around the particle

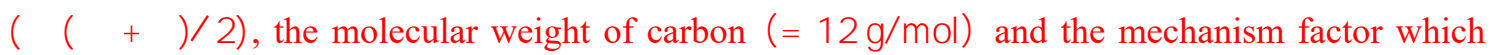
takes unity if the combustion product is $\mathrm{CO}_{2}$ but the value of two if the product is $\mathrm{CO}$. The diffusion coefficient ह depends on the temperature and pressure as:

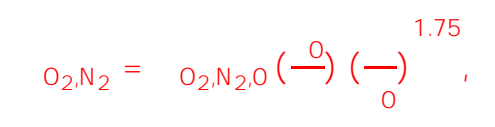

where the subscript 0 means the reference condition. For convenience, the binary diffusion coefficient of oxygen with nitrogen is used for the diffusion coefficient. Generally, the reference pressure and

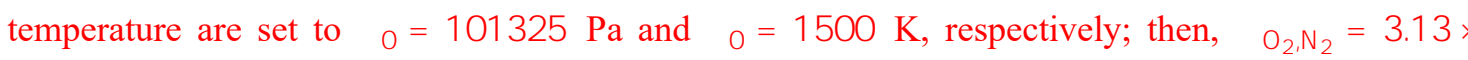

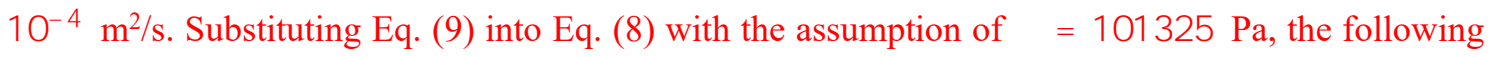
equation can be obtained:

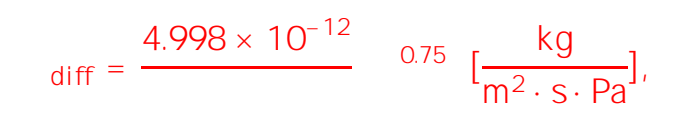

where the value of $v \$ s \rho^{2} \quad \kappa \iota^{p r n t}$ in Eq. (8) depends on the partial pressure unit of oxygen. If the unit of pressure is set to "atm", its value was changed to $\xi d \mathrm{ov}{ }^{2} \mathrm{Kl}^{\rho \rho p}$.

\subsubsection{Particle motion}

According to previous LES studies for pulverized coal combustion [3,7], the particle motion is described by the drag force, force of gravity, and unresolved SGS velocity fluctuation:

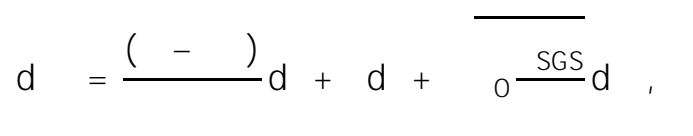

where $\underline{\underline{\mathbf{z}}}$ and $\tau_{\mathrm{फ}}$ are the velocity vectors in the gas and dispersed phases, respectively, and $\bar{\Xi}_{\Omega}$ refers to the particle relaxation time. The second term in the RHS of Eq. (11) corresponds to the forces of gravity; उ $\Omega_{\Omega}$ was evaluated using the following equation [39]:

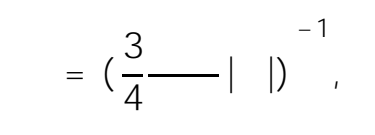




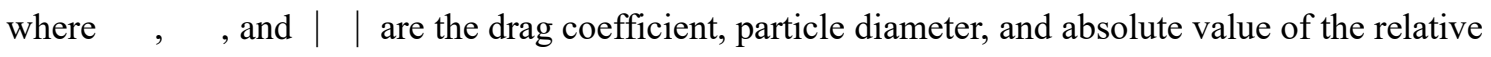
velocity between the gas and dispersed phases, respectively; स: $_{\tilde{p}}$ was evaluated by the following equation proposed by Clift and Gauvin [40], which are available in a wide range of particle Reynolds numbers,'

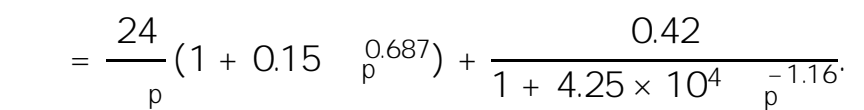

The Clift and Gauvin model can be used until' ' $\quad \lambda^{2} \kappa^{2}{ }^{x \cdot}$ while the classical Schiller and Nauman model can be used until ' $<{ }^{\text {"r }}$. Although the particle Reynolds number was small and would not exceed the applicable range of Schiller and Nauman model in this configuration, Clift and Gauvin model was implemented in our computational code to ensure the relevant solutions even in other configurations where the particle Reynolds number becomes high.

The third term in the RHS of Eq. (11) indicates the effect of unresolved SGS velocity fluctuation on the particle motion, and was modeled in the approach adopted by Bini and Jones [41]; $स_{r i}$ is a model

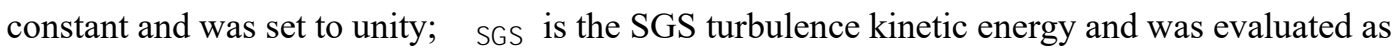

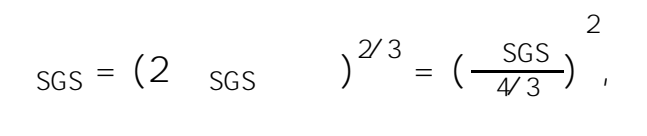

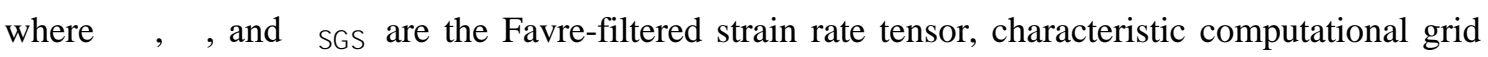

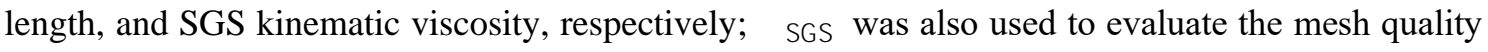
in section 2.7.3; $\overline{5}_{0}$ in Eq. (11) is the particle-turbulence interaction timescale and was given as follows:

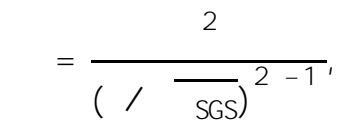

where $I$ was set to 0.8 according to previous studies $[3,7,41]$.

\subsubsection{Particle heat balance}

Pulverized coal particles supplied into the pilot flame were heated via convective and radiative heat transfer. Under the assumption of uniform temperature inside the particle, the particle heat balance can be described as follows:

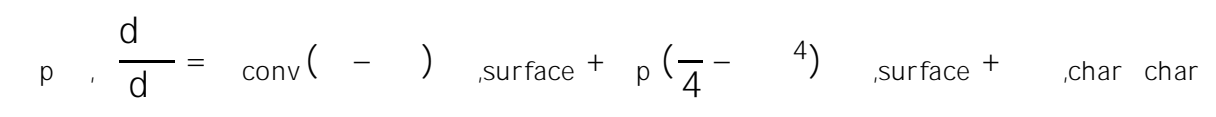

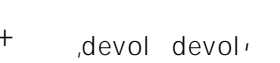

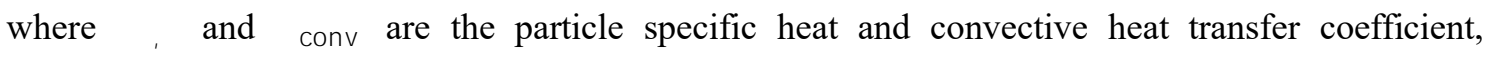
respectively; . , $\mathbf{F}_{\mathrm{N}_{2}}$ and $ढ$ are the incident radiation, particle emissivity, and Stefan-Boltzmann

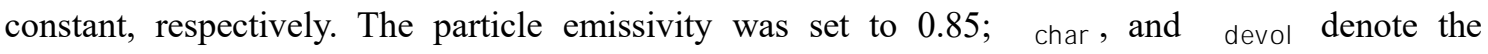


exothermic/endothermic effects owing to char combustion and devolatilization and were set to $\varsigma d \kappa^{2} \quad \kappa^{p}$ and $0.0 \mathrm{~J} / \mathrm{kg}$, respectively. The specific heat of the coal was evaluated by combining those of the volatile matter, fixed carbon, and ash, according to previous studies $[42,43] ;=k_{\mathrm{m} m \mathrm{~m}}$ in Eq. (16) was evaluated from the Nusselt number, which was calculated from the equation of RanzMarshall [44]. The momentum and heat exchanges between the gas and dispersed phases are influenced by the convective flow around the particle during rapid devolatilization. Specifically, this would affect the particle relaxation time and Nusselt number, resulting in a demand for correction, referred to as the Blowing Correction [45]. This correction was implemented into the simulations according to a previous study [46].

\subsection{Combustion modeling using the FPV approach}

\subsubsection{Two-mixture-fraction approach}

In this study, we followed previous studies [7, 9, 23] and constructed look-up tables that can be used in pulverized coal combustion. If we consider the two types of fuel streams, i.e., volatile gas and char off-gas, the following mixture fractions are defined:

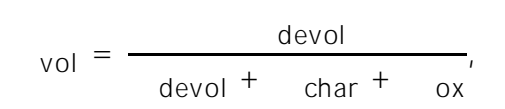

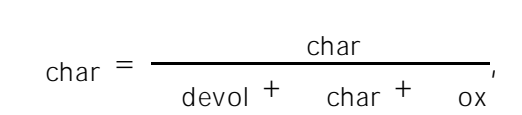

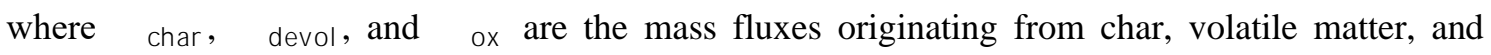
oxidant gas, respectively. The definitions of the two mixture fractions are the same as those in a previous study by Rieth et al. [7, 12, 25]. The denominators of Eqs. (17) and (18) indicate the total

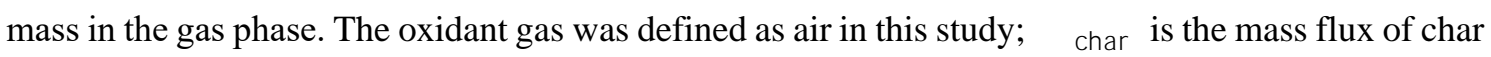
off-gas and has the following relationship with șching

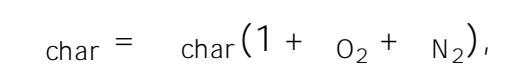

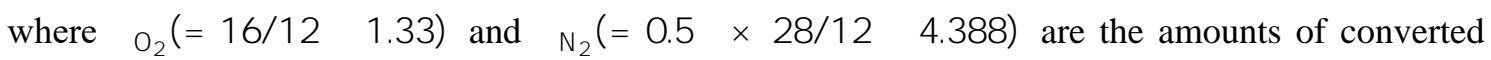
oxygen and nitrogen from the oxidizer to the fuel per unit mass of carbon in char combustion,

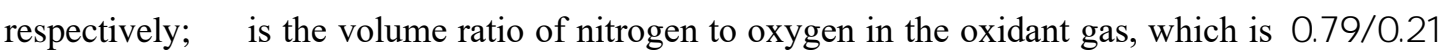
$\mu$ dto in air. Here, șinm includes the mass flux of the oxidizer streams because the oxygen and

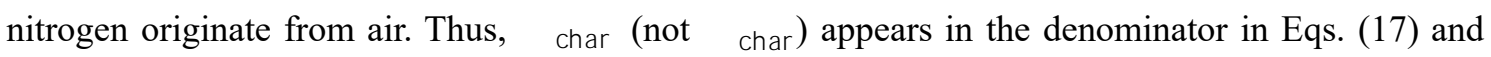
(18). The thermochemical quantities were tabulated as a function of the sum of the two mixture

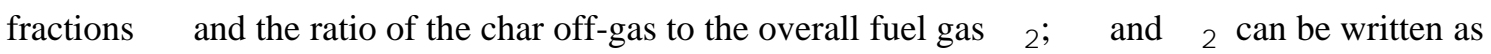
follows

$$
\text { † }
$$




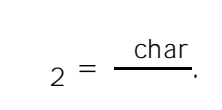

Using $\overbrace{76}$ the composition of the overall fuel can be expressed as

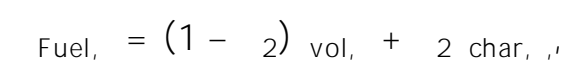

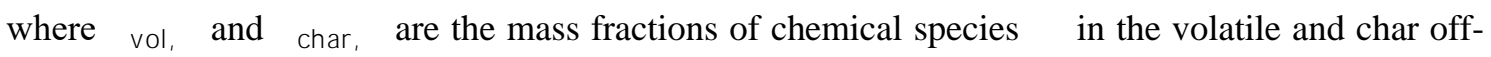

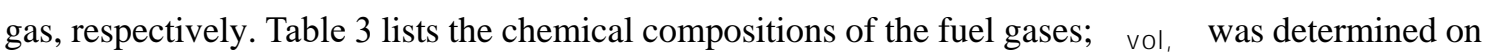
the basis of the proximate and ultimate coal analyses by specifying the chemical species that constitute

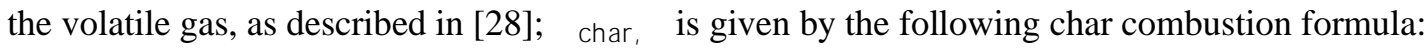

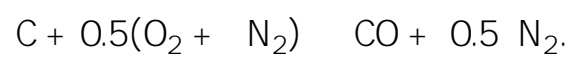

The char off-gas consists of $\mathrm{CO}$ and $\mathrm{N}_{2}$, with volume and mass ratios of $\kappa d_{6} \eta_{\infty} \Phi$ and $\lambda \rho \eta_{\kappa} v \mathrm{r}$ $\iota$ div $\rceil \phi \xi \mu$, respectively.

Aside from the studies on soot formation or tar evolution [47], large hydrocarbons have often been ignored in previous flamelet modeling of pulverized coal combustion. This is because the reaction mechanism accounting for heavy hydrocarbons has not been established and is too expensive for the construction of the look-up table. Thus, the heavier species in the volatile gas have been often replaced by $\mathrm{C}_{2} \mathrm{H}_{2}$. [19, 28, 48, 49]. In addition to the problem of the reaction mechanism, the difficulty in flamelet modeling of large hydrocarbons is related to the omission of large hydrocarbons. Similar to nitric oxides, large hydrocarbons typically form via a chemical process slower than fuel combustion. Although McConnell and Sutherland [47] have recently assessed the effects of coal-derived tar and soot modeling using a steady flamelet model, their work is limited to a priori analysis, and the flamelet modeling of coal-derived tar remains a challenging topic. One of the concerns regarding the omission of heavier volatiles is the change of temperature and major species owing to the difference in chemical compositions between the experiment and simulation. To confirm the effects of large hydrocarbons on the temperature and major species profile, we performed one-dimensional combustion simulations with the heavy volatile, represented as $\mathrm{C}_{6} \mathrm{H}_{6}$. The temperature and major species profile (not shown here) are insensitive to the alteration of large hydrocarbon, indicating that the influence of the

\begin{tabular}{|c|c|c|}
\hline & $\Gamma_{\text {GRAr }}$ & 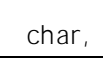 \\
\hline $\mathrm{CO}$ & 0.34 & 0.347 \\
\hline $\mathrm{CH}_{4}$ & 0.55 & 0.0 \\
\hline $\mathrm{C}_{2} \mathrm{H}_{2}$ & 0.11 & 0.0 \\
\hline $\mathrm{N}_{2}$ & 0 & 0.653 \\
\hline
\end{tabular}
replacement of tar by $\mathrm{C}_{2} \mathrm{H}_{2}$ is small. The details of the calculations were summarized in Appendix.

Table 3 Fuel compositions of volatile and char off-gas on a mass basis. 


\subsubsection{Look-up table construction}

To prepare the thermochemical data, one-dimensional calculations of a counter-flow diffusion flame were performed using the FlameMaster [50]. Given the computational cost of the setup of lookup tables, DRM 22 [51] was used as the reaction mechanism according to previous coal combustion simulations [49, 52]. This mechanism comprises 22 chemical species and 103 chemical reactions. In the two-mixture-fraction approach, $\succ_{\pi}$ specifies the overall fuel compositions, as shown in Eq. (22).

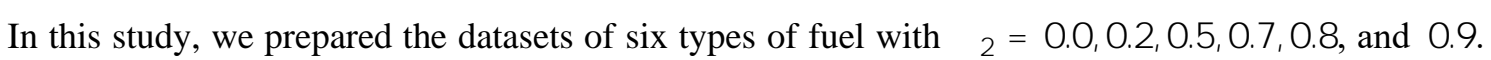
The maximum value of ${ }^{\dagger}{ }_{\pi}$ was set to 0.9 (not unity) because the flame was not ignited owing to a lack of hydrogen atoms. According to previous studies [9, 21], the mass fraction of progress variable $\Gamma_{m a n}$ was defined as the sum of the mass fractions of $\mathrm{CO}_{2}, \mathrm{H}_{2} \mathrm{O}$, and $\mathrm{H}_{2}$.

In the CRIEPI burner, char reactions are not significant. To consider pilot gas exactly, Rieth et al. [19] ignored the char reactions and performed the flamelet-LES using a two-mixture-fraction approach of volatile and pilot gas. However, we regarded this configuration as one of the analytical objects to verify the flamelet modeling of pulverized coal combustion and avoided constructing the table specific to the CRIEPI burner. We prepared the same grid points for the $t^{4}{ }_{T}$ axis as those of our previous work [23].

The one-dimensional calculation does not consider the external effect, such as heat loss by radiation. As the heat exchange between the gas and dispersed phases cannot be ignored in pulverized coal combustion, enthalpy was added to the representative parameters, and additional one-dimensional calculations were performed under different boundary temperatures. When the obtained data were tabulated, the normalized enthalpy at each grid point was defined as follows:

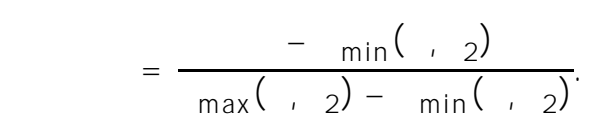

This is because the local enthalpy depends on ${ }^{\circ}$ and ${ }^{t}{ }_{n b}$ The flamelet data along the $=\mathrm{t}_{\mathrm{rGZ}}$-axis was obtained by the calculations for boundary temperatures of 100, 300, and $600 \mathrm{~K}$. For lower enthalpy values, the extrapolation method was used to cover the entire range of enthalpy levels in the later CFD. In addition, the progress variable was also normalized by the maximum and minimum values at each grid point $[31,53,54]$,

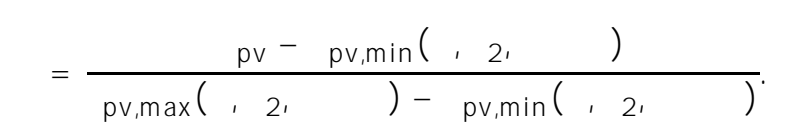

\subsubsection{Turbulent combustion modeling using a presumed PDF approach}

As spatial- or Favre-filtered variables are used in the turbulent simulation, filtered variables should be tabulated in the look-up tables instead of instantaneous variables. When the PDFs of the 
statistical variables, such as the mixture fraction and progress variable, are assumed to be independent, the Favre-filtered variables are defined as follows:

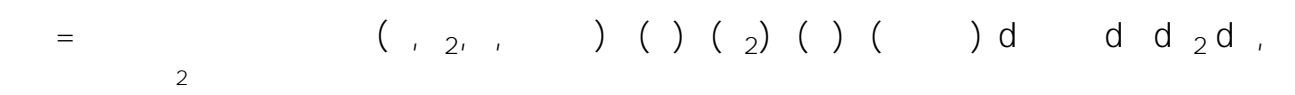

where 4 if ) represents the PDFs of statistical variables., and their functional forms are assumed before the construction of the look-up tables in the presumed PDF approach. A Dirac delta function for

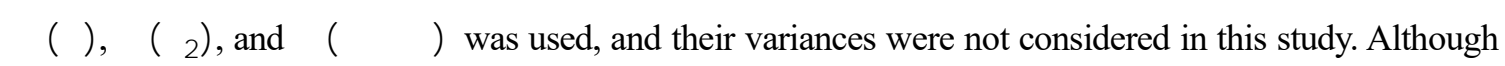

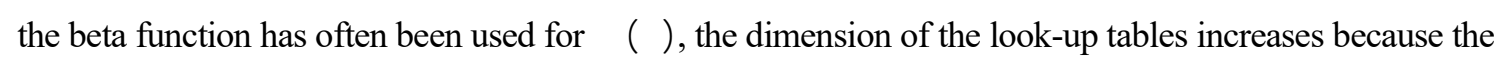
SGS variance appears in the integrand. Then, the tabulated data were prepared for all SGS variances, resulting in the multi-dimensionality of the look-up tables. In a system where the number of representative parameters is large, this multi-dimensionality causes an increased random access memory (RAM) footprint, possibly exceeding the limits of the system. To avoid this problem, we used a top-hat function for $\checkmark$ if $($ ) according to previous studies $[55,56]$. This simple model was originally proposed by Floyd et al. [57]. The top-hat function assumes that all values between the lower and upper limits, denoted by $\succ_{d}$ and $\nearrow_{W}$ respectively, are equally likely, and the functional form can be expressed as follows:

$$
\begin{aligned}
& \text { ৬ڤ }
\end{aligned}
$$

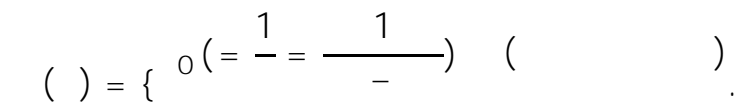

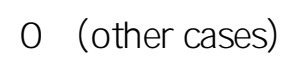

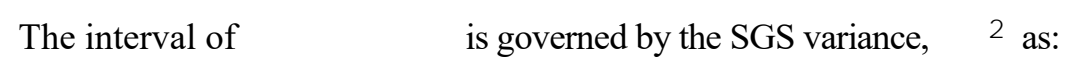

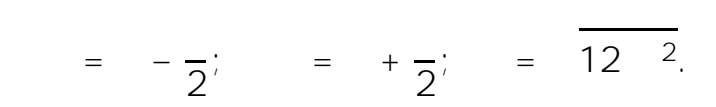

Then, Eq. (25) can be written as:

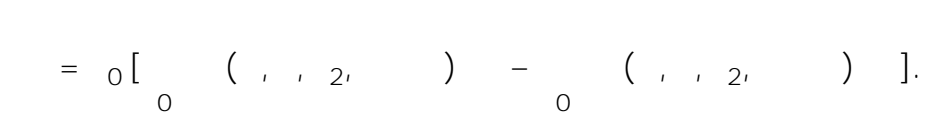

From Eq. (29), the SGS variance does not appear in the integrand. Thus, the dimension of the look-up tables does not increase even in the turbulent simulation because the Favre-filtered variable can be calculated in the CFD simulation as long as the accumulated values from zero to $\widehat{t}_{\mathrm{W}}$ or $\widehat{t}_{d}$ are stored in the look-up tables. The top-hat function actually provides meaningful solutions only when the value of

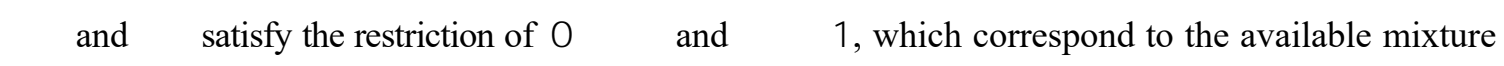
fraction range. As the variation range of the mixture fraction can deviate from the available range depending on the SGS model and target system, Floyd et al. [57] prepared five cases and represented the Favre-filtered variables in various situations using the weighted Dirac delta function. This modification requires the storage of additional integrated values with the Dirac delta function, and the 


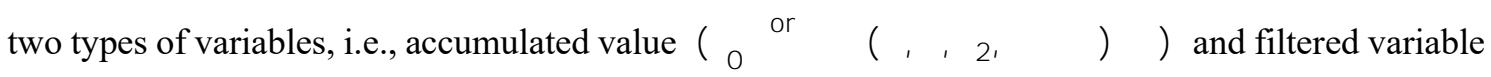

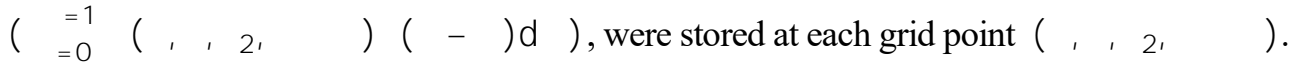

\subsection{Numerical method}

\subsubsection{Discretization schemes and solutions}

The simulation was performed using our in-house code, which was developed at Tohoku University on the basis of the finite volume method [23, 58]. The computational domain was constructed using unstructured grids with approximately five million grids. The second-order AdamsBashforth method was used as the time-integration scheme for the Navier-Stokes equations, while the Euler implicit scheme was used for the other equations. The convective terms were discretized by a blended scheme (combining a central differencing scheme and a third-order upwind scheme at a $95 \%$ to $5 \%$ ratio) in the Navier-Stokes equations, and those in the other equations were discretized by a total variation diminishing (TVD) scheme with min-mod limiters [59]. For the diffusion terms, the central differencing scheme was used in all governing equations. Using a simplified marker and cell (SMAC) method [60], the velocity was coupled with pressure in the solution process, and the Poisson equation of the pressure correction term was solved using the algebraic multi-Grid solver [61]. The other equations were solved using the bi-conjugate gradient stabilized method with polynomial preconditioning (Bi-CGSTAB) [62]. The time steps of the gas-phase calculation were dynamically determined by restricting the Courant number to a maximum of 0.1 at each step, whereas the time steps were fixed at $1 \mu \mathrm{s}$ in the dispersed-phase calculation. Similar to the approach adopted in [14], the flow field was stabilized with only pilot gas, and pulverized coal particles were supplied after a delay of $0.2 \mathrm{~s}$. The time-averaged values were calculated from the sampling data between $t=0.3$ and $0.4 \mathrm{~s}$. The total number of particles supplied into the domain was approximately 1.26 million. The simulations were performed using 60 central processing units (CPUs) on the scalar-parallel computer LX 406Re-2 at the Cyberscience Center of Tohoku University.

The most recent proceedings of the CBC Workshop recommend at least $0.35 \mathrm{~s}$ to obtain converged downstream mean profiles and even longer sampling times for reliable RMS statistics. However, we could not perform this long calculation owing to excessive computational cost, and the sampling period was set to $0.1 \mathrm{~s}$. This sampling period was determined by confirming that the timeaveraged distributions of the fluid properties, such as velocity and temperature, were approximately symmetric. To assess the sensitivity of the LES statistic to the sampling time, the mean and RMS 
values of the axial particle velocities obtained from different sampling periods are compared in the Appendix .

\subsubsection{Boundary conditions}

Only two types of fuel streams can be considered in the two-mixture-fraction approach. However, the target flame comprises at least three types of fuel streams: volatile gas, char off-gas, and pilot gas $\left(\mathrm{CH}_{4}\right)$. Wen et al. [56] suggested the use of three types of mixture fractions to consider all fuel streams and calculated the CRIEPI burner. However, its multi-dimensionality can lead to an excessive memory footprint on the computers, as described in section 2.6.3. To avoid this problem, the simulation was performed on the basis of the two-mixture-fraction approach of volatile and char off-gas in this study. To consider the tertiary stream (pilot gas), the composition of it was replaced by

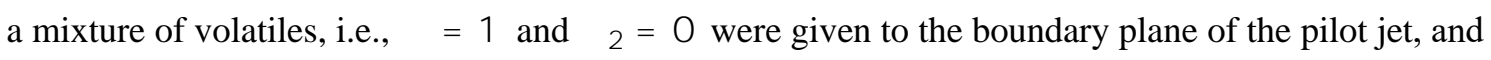
its gas velocity was adjusted to maintain the experimental thermal input [14]. Thus, the uniform profile with a velocity of $2.367 \mathrm{~m} / \mathrm{s}$ was given to the inlet plane of the pilot jet.

Although the inlet velocity of a central jet is important for capturing particle motion in the experiment, the appropriate velocity profile is difficult to reproduce because the fluid flow with ' $\lambda \xi v v$ is in a transient state between laminar and turbulent. We confirmed that the simulations failed to predict the centerline axial particle velocity when the parabolic distributions with an average velocity of $6.4 \mathrm{~m} / \mathrm{s}$ were used for the inlet boundary condition. Accordingly, the inflow profile provided by the CBC Workshop [17] was used with interpolation in this study. Figure 3 shows the axial velocity distributions at the inlet plane generated by various methods. The data labeled as " $\mathrm{CBC}$ " refer to the original data $a_{\mathrm{q}_{\mathrm{z}}}=0.1257859 \mathrm{~ms}$ and include the turbulent fluctuations. The laminar and turbulent profiles were prepared using theoretical equations with the average reference velocity of 6.4 $\mathrm{m} / \mathrm{s}$ without the fluctuating components. The profile of the workshop is closer to that of the laminar flow than that of turbulent flow; however, it does not completely agree with the laminar flow profile. The interpolated data labeled as "This study" in the figure are in sufficient agreement with the original data. More details of the interpolation are shown in Appendix A. The slip wall condition was imposed on the sidewall of the computational domain. Additionally, the outflow boundary condition proposed by Matsushita [63] was used. 


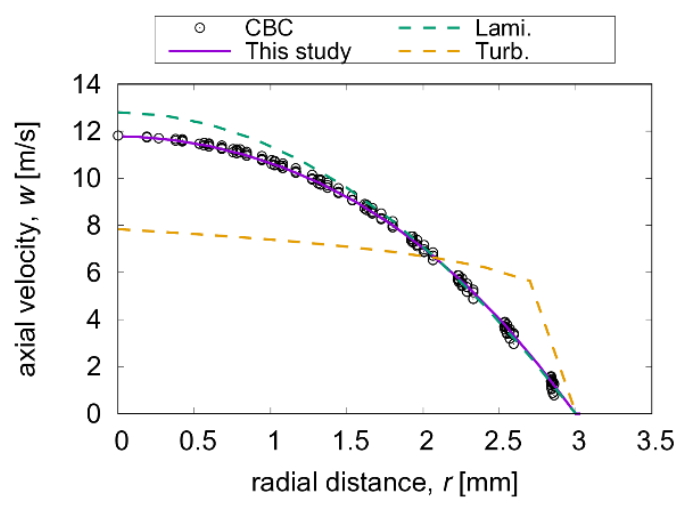

Figure 3 Axial velocity distributions at central jet inlet planes. The data labeled as " $\mathrm{CBC"}$ " refer to the original data at $_{\mathrm{c}_{\mathrm{z}}}=0.1257859 \mathrm{~ms}[17]$.

\subsubsection{Assessment of the mesh quality}

As LES-derived results are dependent on grid-width, the mesh quality was assessed. To verify the mesh quality, Pope [64] defined the indicator ( $(2 \check{d})$ as follows:

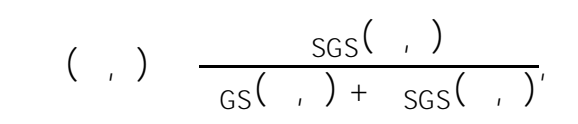

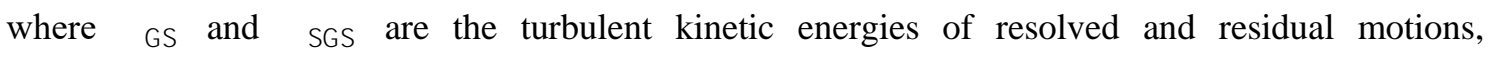
respectively; indicates the fraction of residual kinetic energy to all the kinetic energy and is

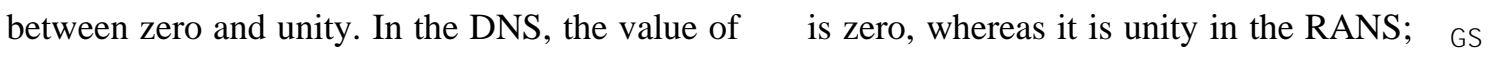
was calculated as follows:

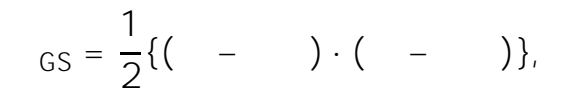

where $\iota y>$ is the averaged values of Favre-filtered velocity, and the time-averaged values were

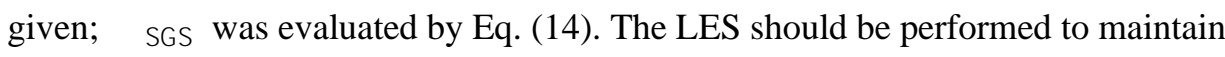

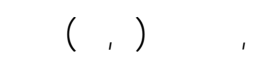

where ${ }_{0_{0}}$, is a turbulence-resolution tolerance and is typically specified to 0.2 , which corresponds to an $80 \%$ resolution of turbulent kinetic energy. In this study, was calculated from the instantaneous and time-averaged velocity values at $\mathrm{m}_{\mathrm{z}}=0.4 \mathrm{~s}$. Figure 4 shows the distributions of the resolved and

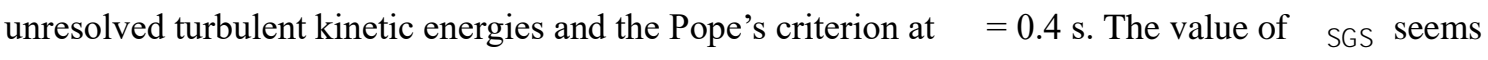
to change periodically at the shear layer of the central and annular jets. Most of the region with 0.5 was located outside of the jets in the upstream region because the denominators of ${ }_{a}$ were infinitely small owing to a small velocity. This region is not a critical area for the flame and particles. Conversely, also increased to approximately 0.5 in the shear layers between the jet and surrounding air. As the particle passed through this region, the RMS velocity of the particles may be influenced by a relatively large value of $\prod_{T_{g}, g}$. Figure 5 shows the histogram of ${ }_{\curvearrowleft}$ in the 
computational domain. Approximately $80 \%$ of the computational grids satisfy the criterion of . (स्स्) a $ı$ d d, indicating that the computational domain has acceptable resolutions.

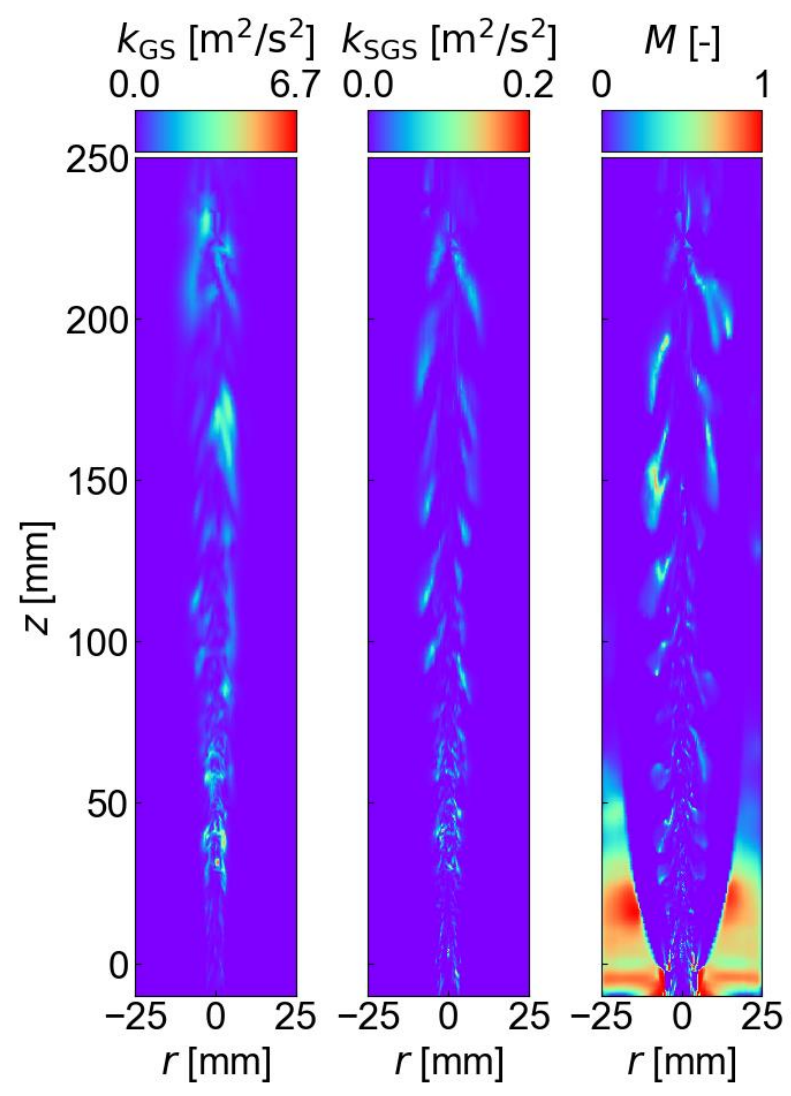

Figure 4 Distributions of the resolved and unresolved turbulent kinetic energies and the Pope's criterion.

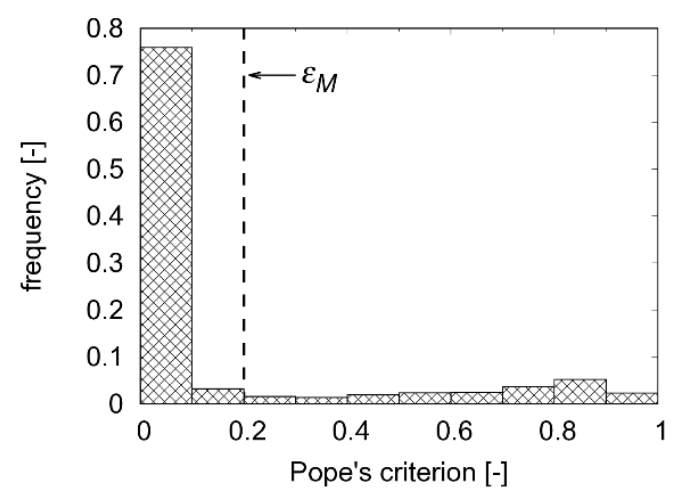

Figure 5 Histogram of the Pope's criterion in the computational domain. 


\section{Results and Discussion}

\subsection{Discussion on the representative parameters of the look-up tables}

The LES results from before and after addition of the coals are separately discussed in this section. For convenience, the two types of flames have been referred to as a "pilot flame" and "coal flame", respectively. Figure 6 shows the instantaneous distributions of the mixture fraction, second mixture fraction, normalized progress variable, and normalized enthalpy at t $_{z_{z}}=0.4 \mathrm{~s}$. As ${ }^{\dagger}=1$ was assigned to the inlet boundary conditions of the pilot gas, the mixture fraction was high near the pilot nozzle and was transported downstream via convection and diffusion. The fuel release from the pulverized coals increased the mixture fraction at the boundary region between the pilot and central jets in addition to the center at the downstream region. The second mixture fraction, which represents the char combustion after devolatilization, also increased further downstream of $३=100 \mathrm{~mm}$. However, its magnitude is small at $\mathrm{Kl}^{{ }^{e} \cdot \mathrm{Tb}}$ order, indicating that char combustion is not significant. The thermochemical quantities of this order were obtained via interpolation of the data at $\rangle_{\pi 6}=0$ and 0.2 stored in our look-up tables, and the accuracy of this treatment should be confirmed. The additional one-dimensional calculations indicated that the maximum temperature in the range of $\mathrm{t}$ a $t_{\pi}{ }_{0}^{\mathrm{a}} \mathrm{\iota} d \mathrm{~d}$ was approximately linear to $\dagger_{\imath \xi}$ Thus, the accuracy of the look-up tables is adequate even for a small $\dagger_{r g}$ The detail of the result is shown in Appendix A.1.

The normalized progress variable is high in most areas where the pilot gas passed because the progress variable generated upon pilot gas combustion was transported downstream. Conversely, low temperature inhibited the onset of the fuel release from the coals and subsequent gas combustion at the center, resulting in the delay of an increase of the normalized progress variable; $=t_{\mathrm{tGZ}}$ considerably decreases at the boundary between the pilot and central jets in the upstream region owing to the heat exchange with the particles. As the heat loss is not significant in the center despite the high particle concentration, the convective heat transfer should be dominant in various passes of heat transfer to the particles. Further downstream, the region where the heat loss occurred was extended by the particle dispersion. This is because the hot pilot gas mixed with cold central jets, and the heat exchange between the gas and particles was promoted at various places. Therefore, the heat loss depends on the gas temperature around the particles as well as the particle concentration when the convective heat transfer is dominant.

Figure 7 shows the flamelet data of the total enthalpies at various boundary temperatures with

$\tau_{\pi 6}=0$ and scatter plots of the instantaneous enthalpy obtained from the FPV-LES of the pilot and coal flames. A comparison of the scatter plots in the pilot flame with flamelet data at $\breve{T}=300 \mathrm{~K}$ highlights the slight heat loss in a wide range of mixture fractions. This heat loss was caused by the radiation and increases in the stoichiometric mixture owing to the increase in temperature and absorbable gas. The heat loss in the coal flame is larger than that in the pilot flame. A large heat loss 


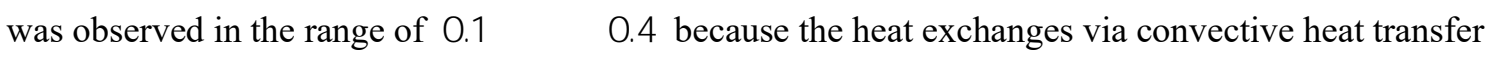
were prompted by the temperature difference between the hot gas and low-temperature coals. From the figure, the present look-up tables can cover these large heat losses by the extrapolations, and the validity of the table was confirmed.

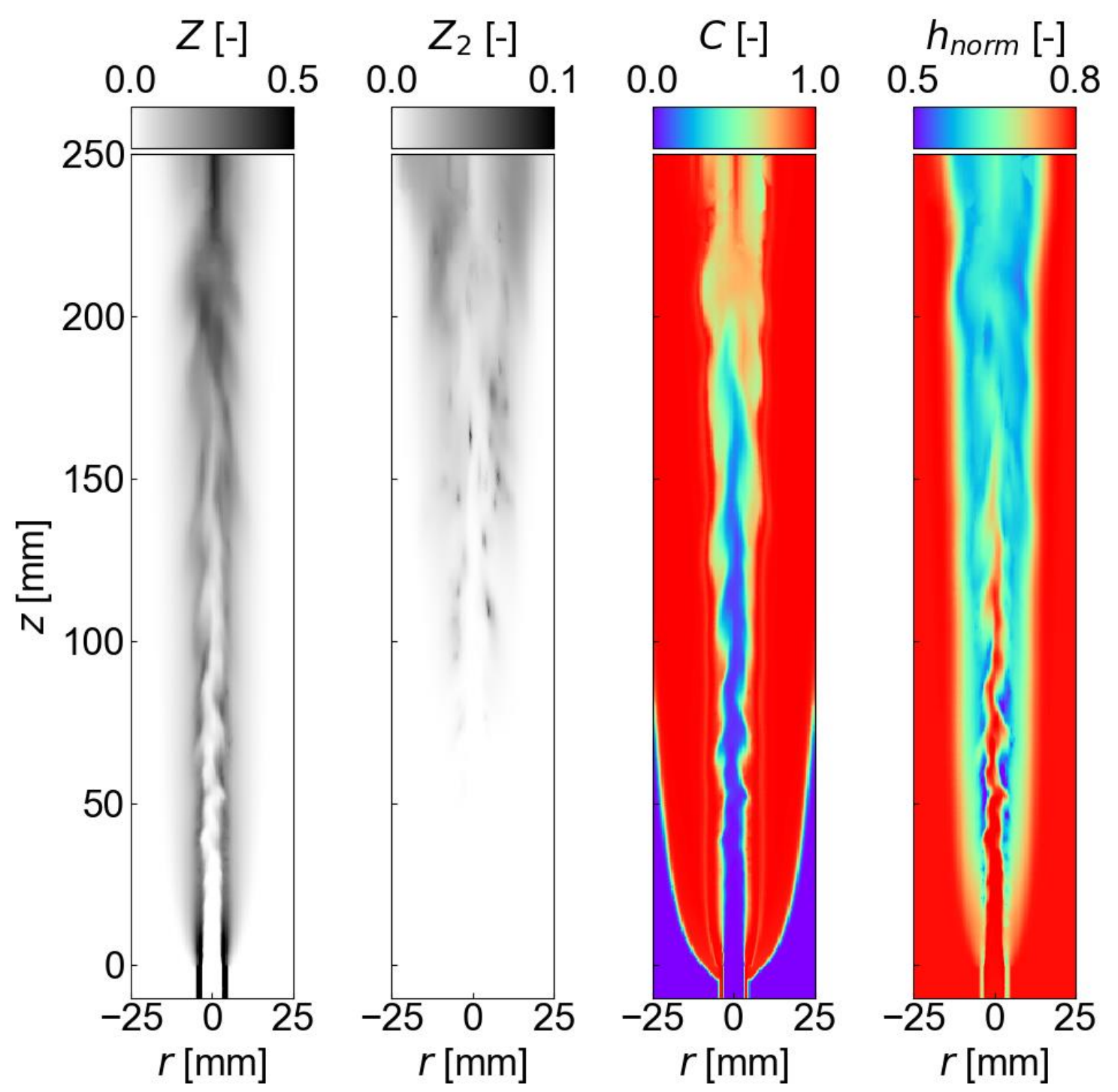

Figure 6 Instantaneous distributions of the mixture fraction, second mixture fraction, normalized progress variable, and normalized enthalpy at $\mathrm{a}_{\mathrm{z}_{\mathrm{z}}}=0.4 \mathrm{~s}$. 


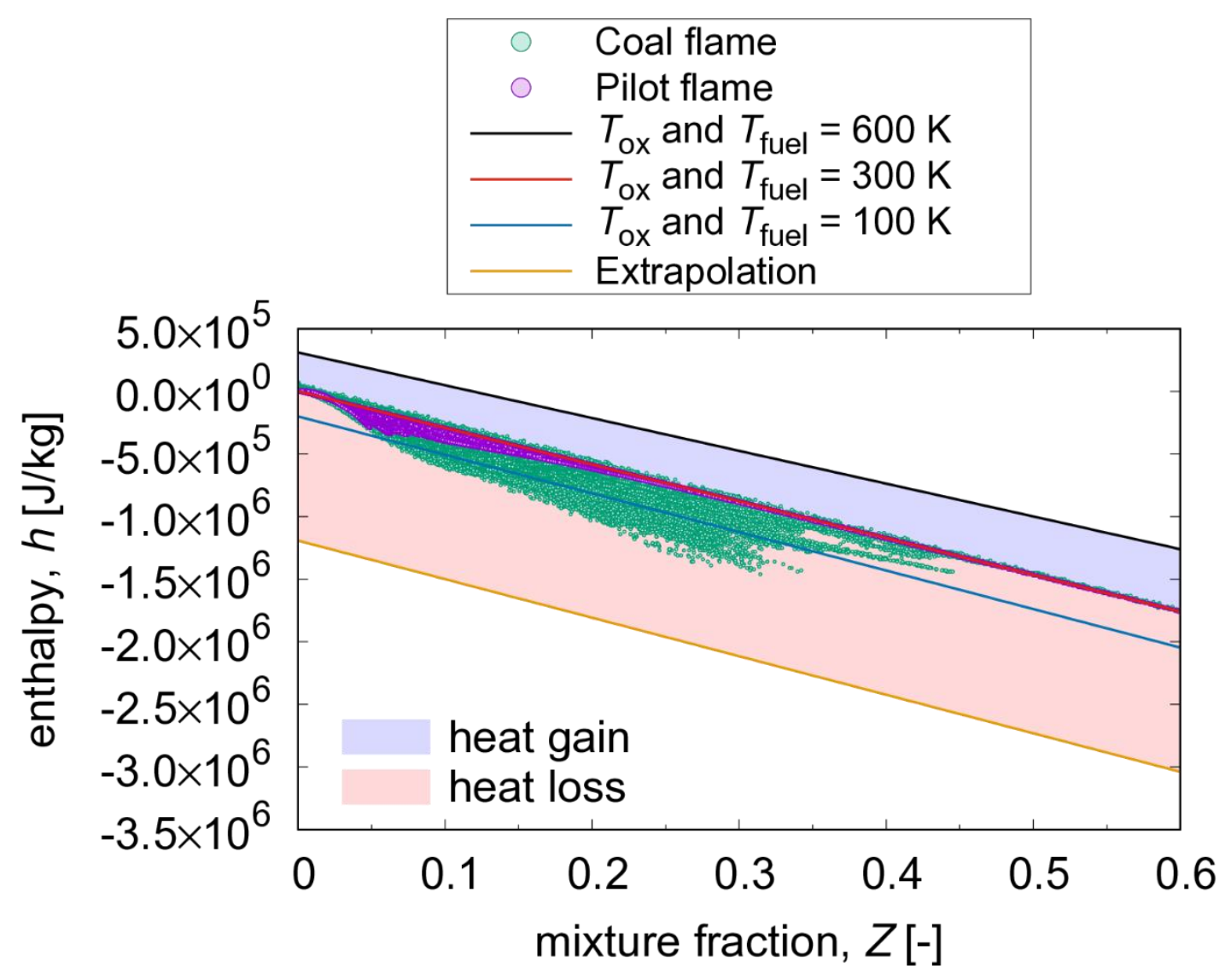

Figure 7 Flamelet data of the total enthalpies at various boundary temperatures with $\overbrace{\pi 6}=0$ and scatter plots of the instantaneous enthalpy obtained from the FPV-LES of pilot and coal flames. The colored area corresponds to the region where heat losses or heat gains occurred.

\subsection{Comparison with experiment in particle motions}

Figure 8 shows the Mie scattering images [14] and particle snapshots. The display range was adjusted to the experimental images for comparison. In the experiment, the particle dispersion was suppressed in the reacting case because the turbulent fluctuation in the gas phase was suppressed owing to the increase in the kinematic viscosity. In addition, spatially non-uniform thermal expansion owing to combustion caused the contrasting particle density. Those changes of particle motion are sufficiently captured by the LES. To confirm the changes of the vortex structure owing to combustion, the $Q$ value [65] was estimated as follows:

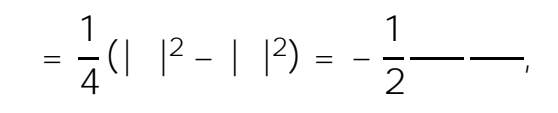

where $T_{\mathrm{u}} \mathrm{X}$ and $\mathrm{X} 2 \mathrm{~T}$ are the magnitudes of the vorticity tensor and rate-of-strain tensor. Instead of instantaneous velocities, Favre-filtered velocities were considered in this study because the 
instantaneous velocities cannot be obtained in the LES. Figure 9 shows the isosurface of $-\mathrm{Kl}^{\varkappa}$ $\mathrm{s}^{-2}$. In the non-reacting case, small vortices were widely distributed, whereas the large helical structure was observed around a central jet in the reacting case. These different vortex structures between the non-reacting and reacting cases had a significant impact to the particle motion.

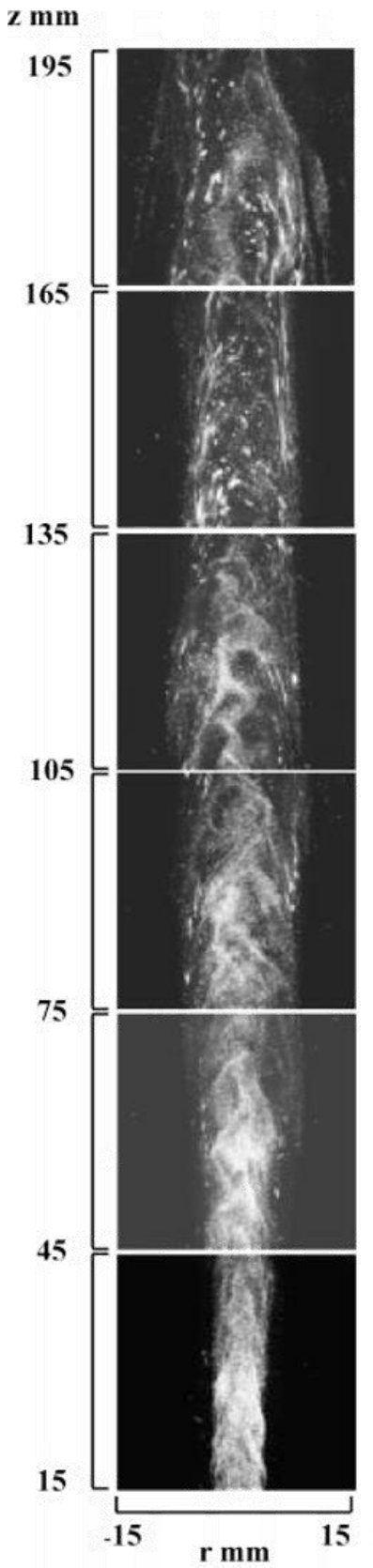

(a) Combusting case
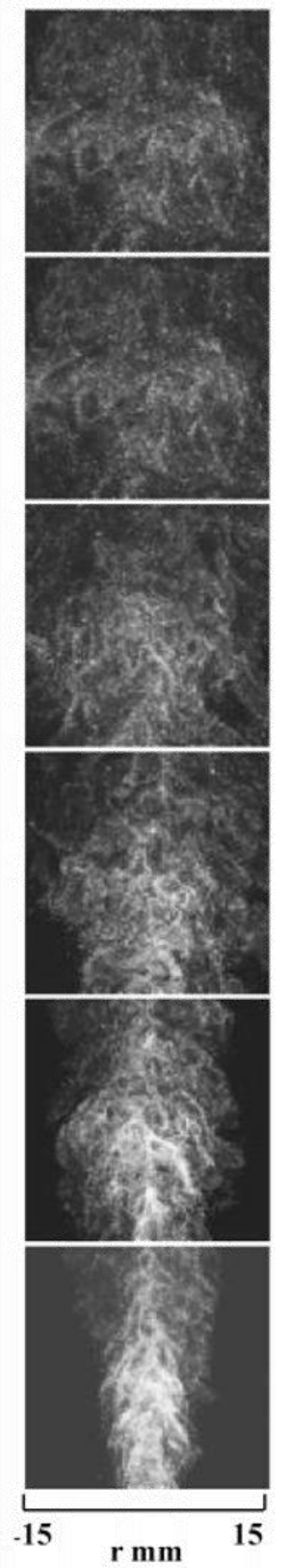

(b) Non-Combusting case

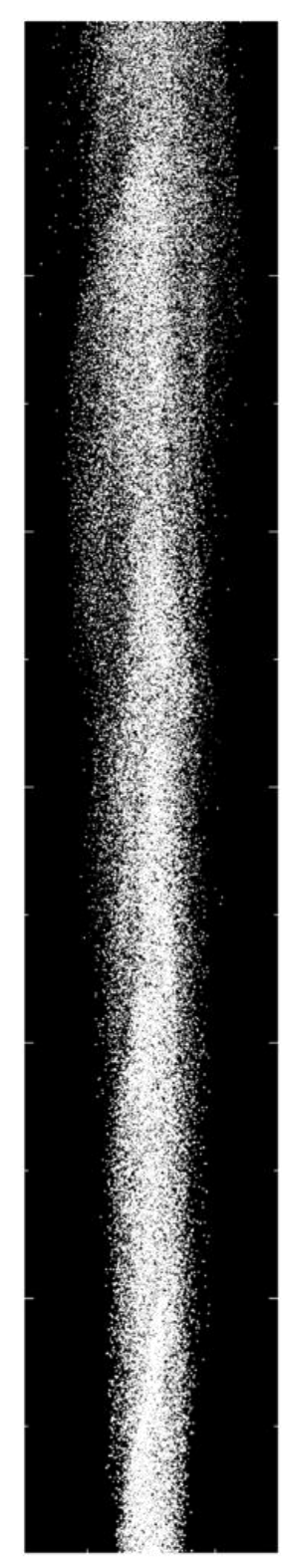

(a) Combusting case

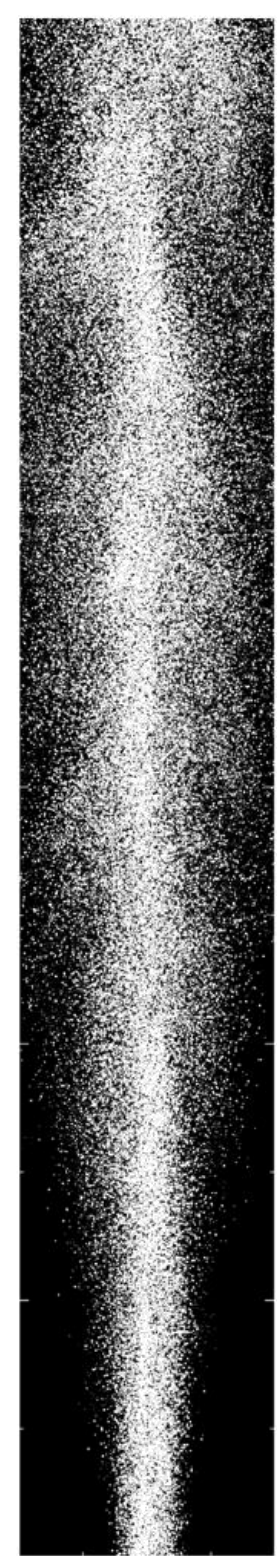

(b) Non-Combusting case

Figure 8 Comparison of Mie scattering images [14] (left) and coal particle snapshots in the simulation at an elapsed time of $0.4 \mathrm{~s}$ (right). The Mie scattering images are reprinted with permission from [14], Copyright (2005) American Chemical Society. 

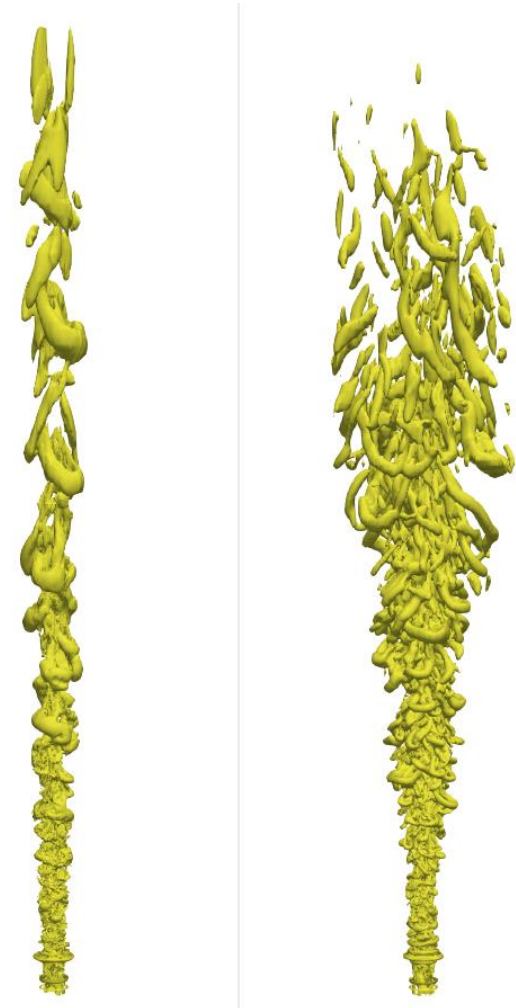

Figure 9 Isosurface of the $\mathrm{Q}$ values of $\kappa \iota \mathrm{s}^{-2}$ at $t=0.4 \mathrm{~s}$ (left: reacting case, right: non-reacting case).

Figure 10 shows the axial distributions of the mean and RMS axial particle velocity. To calculate the statistics, the axial distance between $z=0$ and $210 \mathrm{~mm}$ was divided into 50 sections, and the conditional number-averaged value was calculated in each section using the data within from the centerline. Note that the presented numerical error bars are not the same as RMS values because they are weighted by their parcel numbers, which depend on the initial particle diameter in this study. Initially, we focus on the mean values and discuss the changes of particle motion between the reacting and non-reacting cases. In the reacting case, the decrease of gas-phase velocity was smaller because the dissipation of momentum energy decreases. Then, the decrease in particle velocity was also smaller than that in the non-reacting case, and the particle motion in the experiment could be reproduced by the LES. The smaller standard deviations in the reacting case also indicate that the gasphase fluctuations become small, which is consistent with the changes of the vortex structure, as shown in Figure 9. However, in the upstream at $\mathrm{z}=0-90 \mathrm{~mm}$, the LES slightly underestimates the mean values in the non-reacting case. Because a large difference is observed in the upstream data, this departure may be attributable to the inlet condition. The upstream difference in the non-reacting case is significant for the RMS values, and the LES underestimates the downstream data. Conversely, the difference becomes small in the reacting case even in the RMS values. This may be explained by the 
difference in the factors involved in turbulence between the reacting and non-reacting cases. In the reacting case, the turbulence developed through a rapid change of the fluid property owing to combustion in addition to the shear stress in the boundary region between the central and pilot jets, while the shear stress contributes primarily to the turbulence development in the non-reacting case. Thus, the effect of the inlet boundary conditions in the reacting case was smaller than that in the nonreacting case.

Figure 11 shows the radial distributions of the mean and RMS axial particle velocities. In the non-reacting case, the mean and RMS axial velocities predicted by the LES sufficiently agree with those of the experiment, although a slight difference is observed in the RMS values. However, the difference between the LES and experiment is obvious in the reacting case. For the mean values, the LES underestimates the experimental values particularly in the outer region. In addition, the LES overestimates and underestimates the RMS values in the respective inner and outer regions. The deviations of the RMS values in the upstream region could be caused by the modification of the pilot gas flow rate, which was set to slightly higher values than those in the experimental conditions. In addition, the overestimated RMS values may be related to the mesh resolutions at the shear layer because the deviation of the RMS value from the experiment in the previous DNS [26] was smaller than that in this study.

These errors were also observed in the previous study by Rieth et al. [19]. They stated that the error was attributable to the difference in the heat and mass release via devolatilization and volatile combustion. The sensitivity of the LES results to devolatilization modeling, i.e., chemical species and kinetic parameters, are also confirmed in section 3.3 and can result in decreased prediction accuracy. In the DNS by Hara et al. [26], the axial particle velocities were also underestimated in the outer region. They concluded that the additional air supply in the experiment, described in section 2.1, should increase the difference because its influence was not considered in the simulation. Furthermore, the inlet velocity of the co-flow could influence the particle axial velocities, as an alternate explanation of the difference. The amount of induced air depends on the combustion behavior near the pilot flame because the target system is the open flame. Although the inlet velocity of the co-flow was set to 0.6 $\mathrm{m} / \mathrm{s}$ in this study on the basis of previous studies $[3,28]$, its value was different in other studies, e.g., $8 \%$ of the bulk velocity [18], $1.5 \mathrm{~m} / \mathrm{s}$ [20], and $0.25 \mathrm{~m} / \mathrm{s}$ [26]. Note that the bulk velocity was approximately $1.32 \mathrm{~m} / \mathrm{s}$ in our simulation and $8 \%$ of the velocity corresponded to $0.1 \mathrm{~m} / \mathrm{s}$.

Considering the validity of the LES statistics, the number of samples decreased in the outer region, and reliable statistics may not have been obtained. Figure 12 shows a histogram of the number of samples used to calculate the radial distributions of the particle axial velocities. Moving from the center to the outer side, the number of particles increased because the sampling volume, i.e., crosssectional area, increased. However, the number of samples decreased after reaching the peak because the particles were not as dispersed. This small number of samples at large radii could decrease the 
accuracy of the predictions owing to poor statistics. As this problem occurs in the experiment, the influence of the experimental uncertainties may be included in the above comparison.

(a) mean values

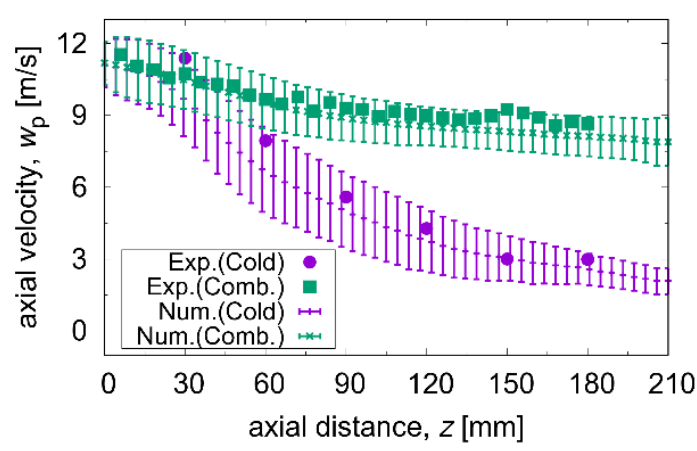

(b) RMS values

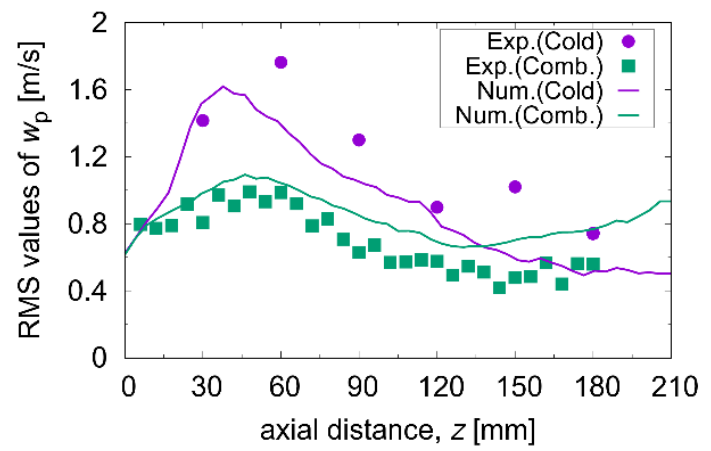

Figure 10 Axial distributions of the mean and RMS axial velocities of the coal particles. The experimental values were extracted from [14]. "Cold" and "Comb." represent the non-reacting and reacting cases, respectively. The error bars on the mean values represent the standard deviations.

(a) mean values

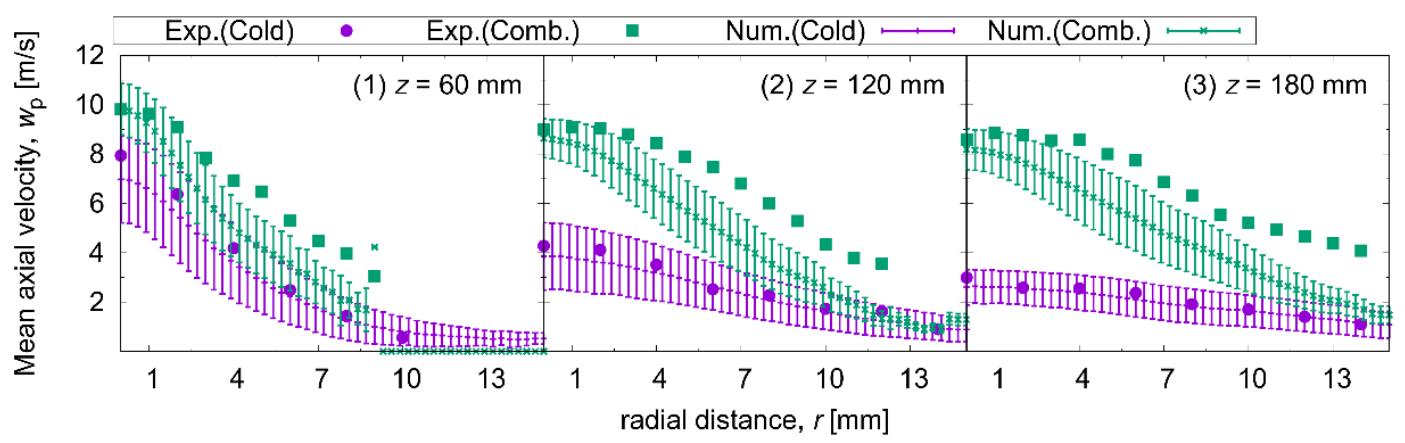

(b) RMS values

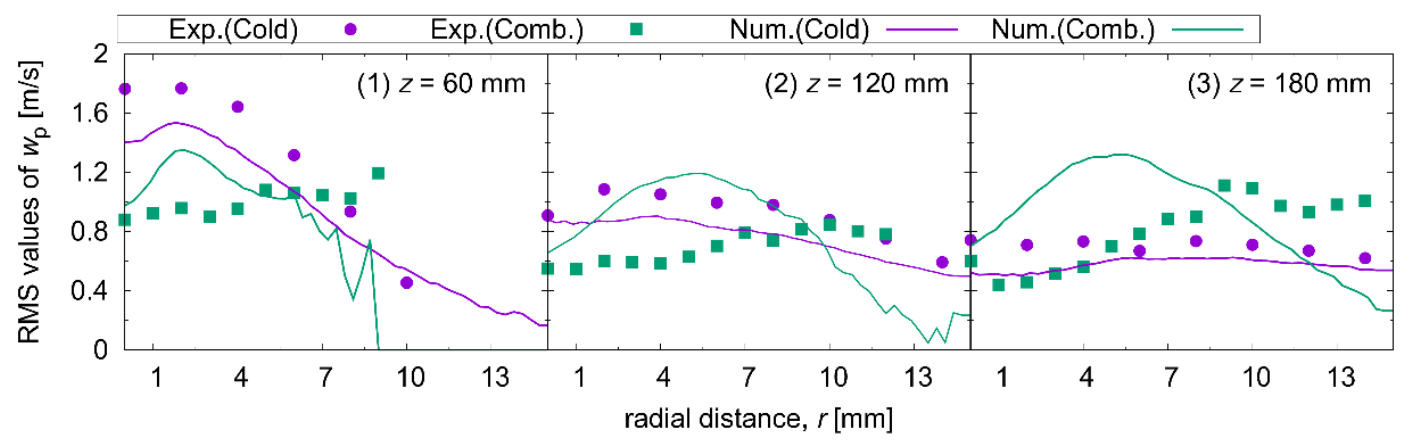

Figure 11 Radial distributions of the mean and RMS axial velocities of the coal particles. The experimental values were extracted from [14]. "Cold" refers to the non-reacting case. The error bars on the mean values are the standard deviations. 


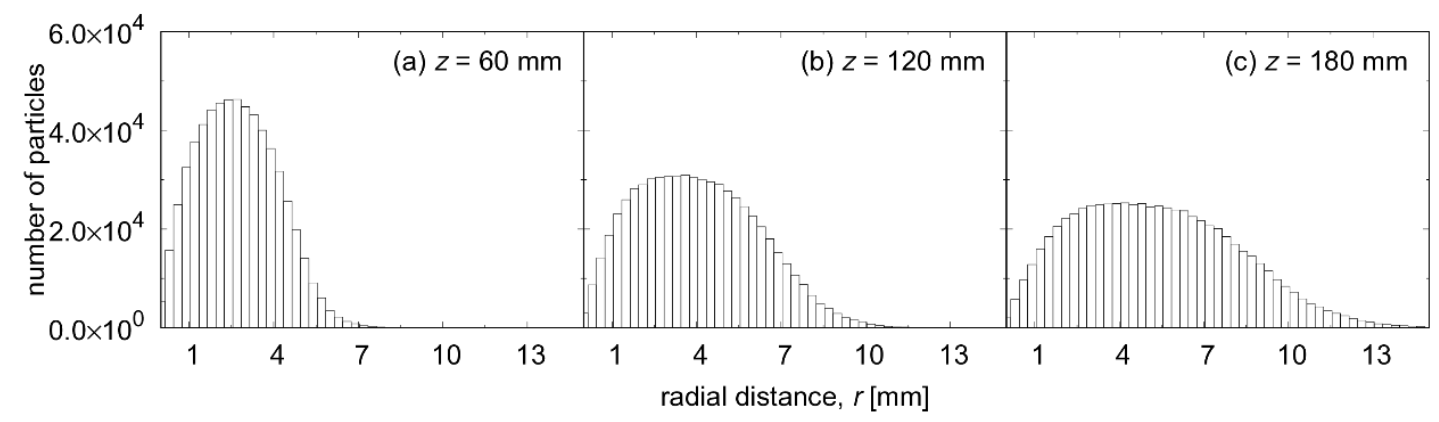

Figure 12 Histogram of the number of samples used to calculate the radial distributions of the particle axial velocities in the reacting case.

\subsection{Comparison with previous results in species distributions}

To compare the present LES with previous results as well as experimental data, the numerical solutions in previous studies $[3,11,19,26]$ were used. The data labeled as "Franchetti et al." were obtained from the LES [3] with the EBU model by Hu et al. [66]. In the DNS [26], the combustion of volatile matter and $\mathrm{CH}_{4}$ were considered as a global two-step reaction model. Wen et al. [11] incorporated the multi-regime flamelet model into an LES. In the multi-regime flamelet model, the look-up tables generated from the premixed and diffusion flamelet were switched according to the flame index. Furthermore, Rieth et al. [19] ignored the char combustion and used the two-mixturefraction approach of volatile matter and $\mathrm{CH}_{4}$ in the LES. Table 4 lists the Q-factor and kinetic parameters of devolatilization in this study along with those from a previous study. The parameters as per Rieth et al. [19] were not written in the table because the chemical percolation model for the devolatilization (CPD) model was directly coupled to the LES. The parameters in Wen et al. [11] and Franchetti et al. [3] are the same.

To confirm the differences in the devolatilization behaviors, the histories of volatile yield were assessed by simple calculations of

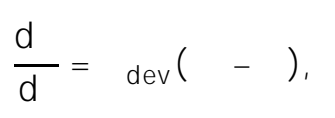

under the representative heating rate; $\nmid$, and $\nmid$ are the initial and released volatile yields in the coal, respectively. First, the axial distribution of particle temperature on the centerline was evaluated and used to calculate the representative heating rate. Figure 13 shows the axial distributions of the averaged particle temperature on the centerline. The residence time calculated using the mean axial velocity (shown in Figure 10 a) was also shown in the second $x$-axis of the figure. The heating rate was small in the upstream region and gradually increased from approximately $z=90 \mathrm{~mm}$. In addition, the standard deviations increased because the various particles that have different thermal histories passed 
through the centerline. Using the transient particle temperatures along the centerline, the effects of the reaction parameters on the volatile evolutions were investigated. Figure 14 shows the transient behavior of the volatile yields under the various reaction parameters. When the parameters of Franchetti et al. [3] and Wen et al. [11, 28] were used, the volatile was released earlier than that in the other groups because the activation energy was smaller.

Figure 15 shows the axial distribution of the measured [14] and calculated volume fractions of $\mathrm{O}_{2}$ and $\mathrm{CO}_{2}$. The numerical solutions in this study were compared to reference solutions by Franchetti et al. [3]. Although the reference solutions overestimate the $\mathrm{O}_{2}$ consumption rate owing to the infinitely fast chemistry of the EBU model, this study reproduced the experimental values because the chemical kinetics based on the detailed chemistry were included in the look-up tables. Focusing on the $\mathrm{CO}_{2}$ distribution, this study underestimates the experimental values. The $\mathrm{CO}_{2}$ underestimation was reported, and the experimental error was identified in previous studies [26, 28]. The previous studies stated that $\mathrm{CO}$ was oxidized to $\mathrm{CO}_{2}$ after gas sampling, and the experimental $\mathrm{CO}_{2}$ volume fraction may have been overestimated.

The solutions in this study are closest to those in the DNS because of the similar Q-factor and kinetic parameters for devolatilization. A comparison of the simulation results between this study and Wen et al. [11] indicates that $\mathrm{O}_{2}$ is more consumed, i.e., combustion is promoted, by the premixed flamelet. They compared the results of the multi-regime flamelet model and the FPV approach, confirming that $\mathrm{O}_{2}$ consumption was suppressed in the FPV approach. The difference in the volatile gas composition and devolatilization parameters would result in a departure from the solution by Rieth et al. [19]. Although differences between this study and a previous study were observed, the overall tendency is consistent with that of a previous study, and the validity of this simulation was ensured.

Table 4 Q-factor and kinetic parameters of devolatilization in this study and a previous study.

\begin{tabular}{|c|c|c|c|c|c|}
\hline & This study & Franchetti et al. & $\begin{array}{l}\text { Hara et al. } \\
\left(\mathrm{C}_{\alpha} \mathrm{H}_{\beta} \mathrm{O}_{\gamma}\right)\end{array}$ & Wen et al. & Rieth et al. \\
\hline Q-factor & 1.62 & 1.9 & 1.62 & 1.9 & - \\
\hline$A_{\text {dev }}[1 / \mathrm{s}]$ & od $\kappa^{2} \quad \mathrm{Kl}^{r r}$ & $v v \pi v$ & $\lambda \phi^{2} \quad \kappa l^{r r}$ & $v v \pi v$ & - \\
\hline$E_{\mathrm{dev}}[\mathrm{kJ} / \mathrm{kmol}]$ & $v q d \pi^{2} \quad \kappa \iota^{r r}$ & $\kappa 屯 \kappa \varsigma^{2} \quad \kappa \iota^{r r}$ & $\mu \mathrm{dt}^{2} \quad \kappa \mathrm{l}^{r r}$ & $\kappa \bigotimes \kappa \varsigma^{2} \quad \kappa \iota^{r r}$ & - \\
\hline Reference & - & {$[3]$} & [26] & {$[11]$} & [19] \\
\hline
\end{tabular}




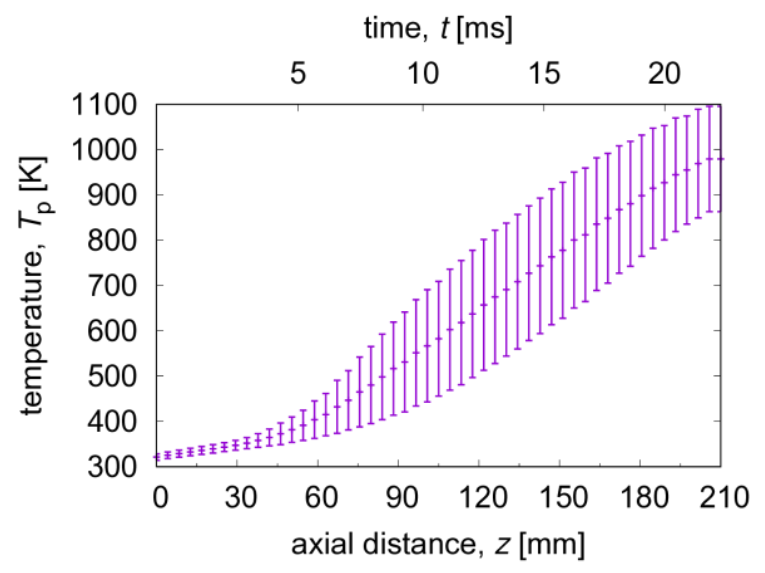

Figure 13 Axial distributions of the averaged particle temperature on the centerline. The error bars represent the standard deviations.

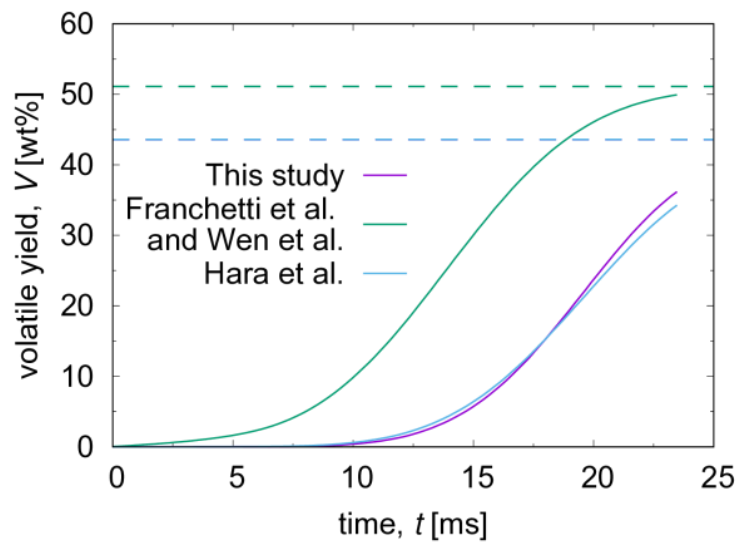

Figure 14 Transient behavior of the volatile yields under the various reaction parameters. The dashed lines represent the initial volatile yields, which depend on the Q-factor.
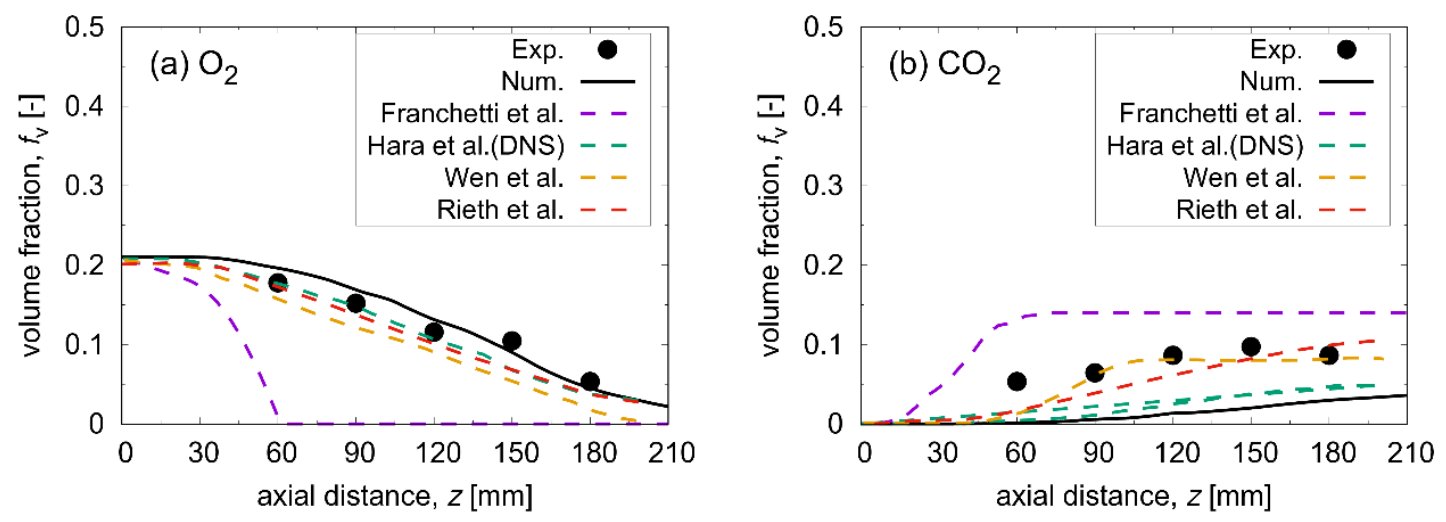

Figure 15 Axial distributions of the measured [14] and calculated volume fractions of $\mathrm{O}_{2}$ and $\mathrm{CO}_{2}$.

For validation, the numerical solutions in previous studies $[3,11,19,26]$ are also shown. 


\subsection{Effects of coal supply on overall combustion behavior}

\subsubsection{Overview}

Figure 16 shows the instantaneous distributions of the gas temperature and mass fractions of $\mathrm{OH}$ and $\mathrm{CO}_{2}$ in the pilot and coal flames. The pilot gas was ignited immediately above the outer nozzle and stably burned. Here, $\mathrm{OH}$, which is an important intermediate species of combustion, was high at the boundary layer of the pilot gas and co-flow gas in the upstream region. As the fuel spread further downstream, the reaction zones expanded to the inside of the flame, and the high-temperature zone formed in the center. However, slightly downstream, the low-temperature region was observed at $\mathrm{z}=$ $70-110 \mathrm{~mm}$. Therefore, the temperature fluctuated because the turbulence and high- and lowtemperature region pass alternately at the tip of the central jet. The distribution of $\mathrm{CO}_{2}$ is almost the same as that of temperature. The temperature distribution of the pulverized coal flame is similar to that before the coal supply just above the pilot nozzle because the effects of pulverized coals on the flame are minimal in this region. However, the temperature remains low at the center, even downstream, whereas it exceeds $2000 \mathrm{~K}$ at $\mathrm{z}=60 \mathrm{~mm}$ in the pilot flame. This is because of the latent heat of pulverized coal, which is supplied from the center nozzle. The effects of coals via heat loss also appeared in the $\mathrm{OH}$ distribution. The high-OH region in the center of the pilot flame disappeared in the coal flame; however, another high-OH region formed at the outer edge of the flame extended downstream. This is because the fuel consumption decreased in the center in addition to the fuel release from the pulverized coals in the downstream region. As shown before the supply of pulverized coal, the distribution of $\mathrm{CO}_{2}$ is similar to that of temperature. 
(a) pilot flame $(t=0.2 \mathrm{~s})$

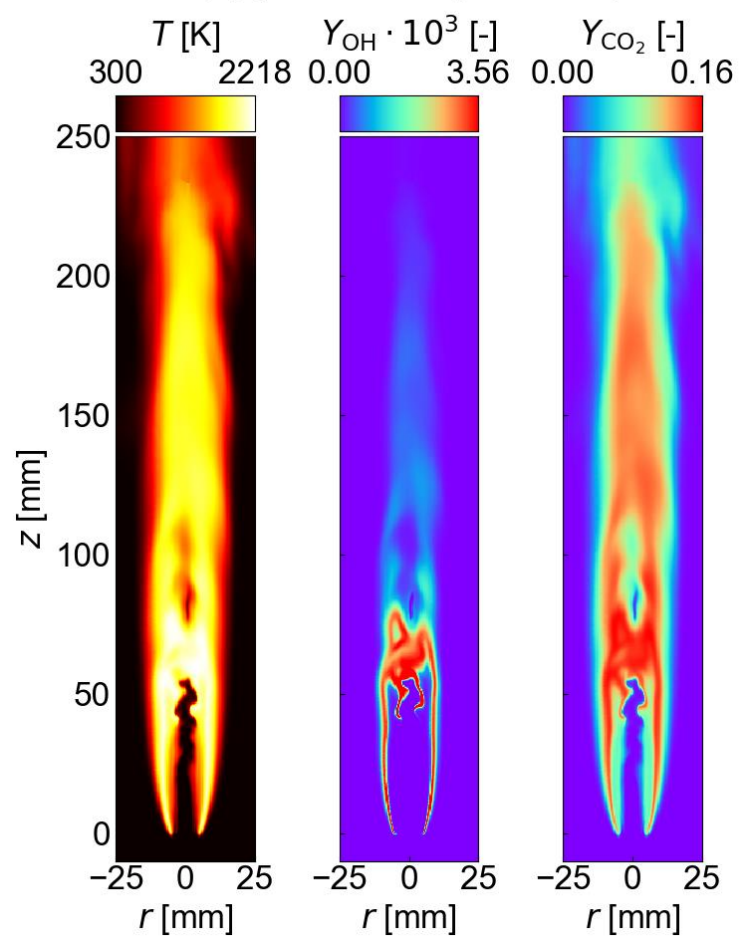

(b) coal flame $(t=0.4 \mathrm{~s})$

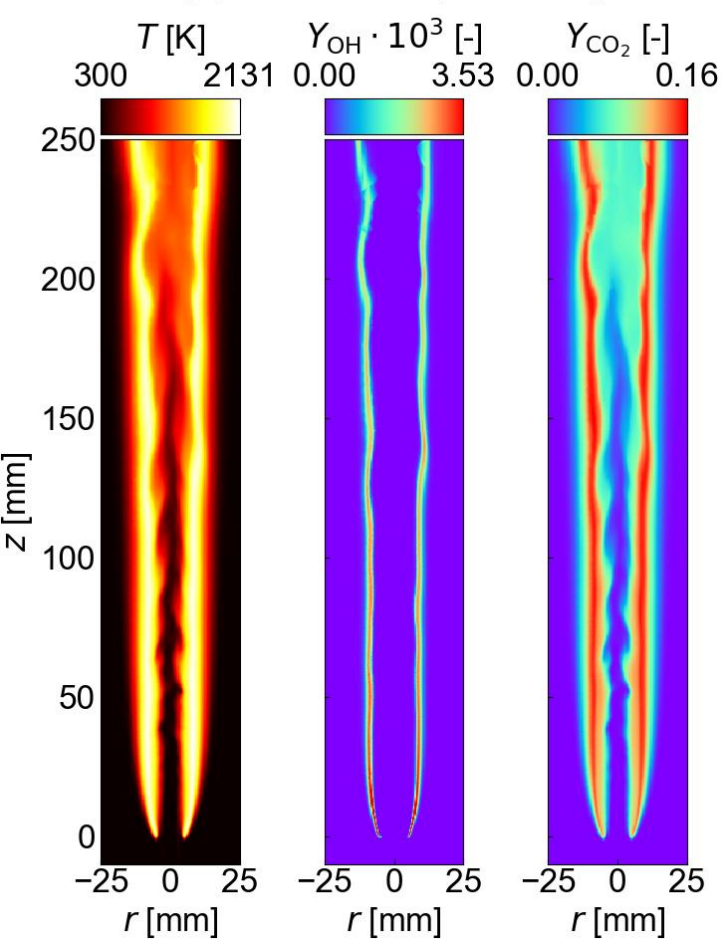

Figure 16 Instantaneous distributions of the gas temperature and mass fractions of $\mathrm{OH}$, and $\mathrm{CO}_{2}$ before and after the supply of pulverized coals.

\subsubsection{Heat loss}

Figure 17 shows the axial distributions of the time-averaged gas temperature and total enthalpy on the centerline. In the pilot flame, the temperature increases around $z=30 \mathrm{~mm}$ and then remains high, even in the downstream region. This temperature increase implies that the high-temperature gas generated by pilot gas combustion mixes with the low-temperature central jet between $z=30$ and 90 $\mathrm{mm}$ in the center. The enthalpy gradually decreases from $z=30 \mathrm{~mm}$ to the downstream side because the high-temperature combustion products, which cause radiative heat loss, are generated in this region. Although the temperature increases near $\mathrm{z}=30 \mathrm{~mm}$ in the coal flame, large temperature changes, as seen in the pilot flame, are not observed. This can be explained by the sensible heat of the pulverized coal, and that fact that it also affects the enthalpy. As the particles were dispersed with increasing distance from the inlet nozzle, the particle concentrations on the centerline should decrease in the downstream region. However, the difference between the pilot and coal flames increases to the downstream side, whereas it is small in the upstream region. This result suggests that other factors in addition to particle concentration determine the degree of heat loss.

Figure 18 shows the radial distributions of the time-averaged gas temperature and total enthalpy before and after the pulverized coal supply. The pilot flame has a moderate peak in temperature near $r=7 \mathrm{~mm}$ at $z=60 \mathrm{~mm}$. The peak shifted inward in the downstream region because of the mixing of 
the hot combustion products and the central jet. The decrease of enthalpy in the high-temperature region exhibits radiative heat loss by combustion products. The temperature at $\mathrm{z}=60 \mathrm{~mm}$ in the coal flame agrees well with that in the pilot flame at the outer side even though the temperature remains low in the center. The similar distributions in the outer side are because the particles have not yet dispersed. The enthalpy decreases in $r=3.5-4.0 \mathrm{~mm}$, where the pilot nozzle is located, suggesting that the effects of heat loss are significant only in the boundary layer between both jets in the upstream region. As the particle disperses radially at $z=120$ and $180 \mathrm{~mm}$, a difference between the pilot and coal flames can be seen even on the outer side. The Reynolds number is small, and the turbulent flow and particle concentration are still large at the center. Thus, the temperature peak observed at $z=60$ $\mathrm{mm}$ is maintained in the downstream region as well. This shape is significantly different from that in the pilot flame alone. A negative peak of enthalpy is observed at $z=60$ and $120 \mathrm{~mm}$ and is located at the shear layer of both jets, where the gas temperature and particle concentration are high. The gas temperature is low in the inner side of the peak, whereas the particle concentration decreases in the outer side. Therefore, the heat loss is sensitive to the gas temperature and particle concentration in the pulverized coal flame. The negative peak of enthalpy disappears at $z=180 \mathrm{~mm}$ because the gas temperature increases even at the center, and the particles are dispersed to the outer side.

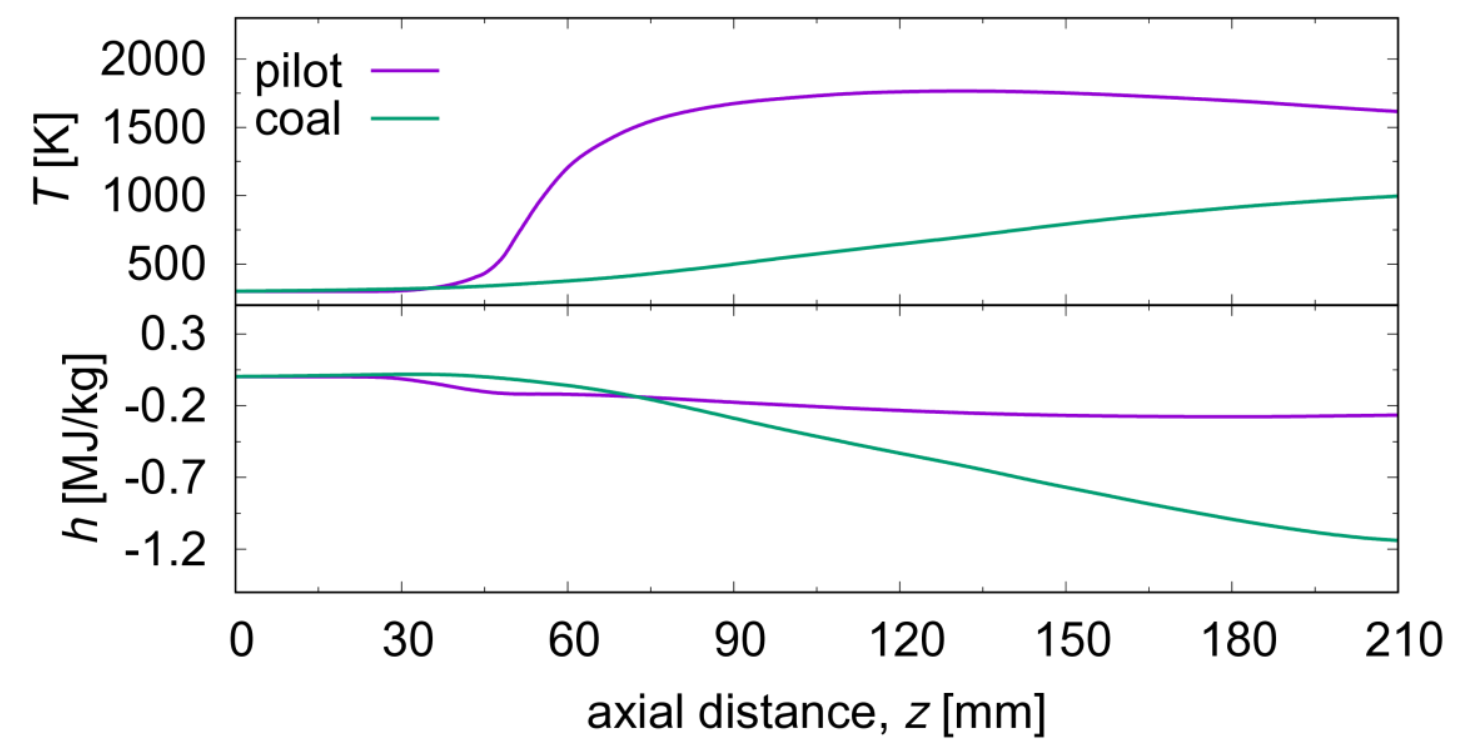

Figure 17 Axial distributions of the time-averaged gas temperature and total enthalpy on the centerline before and after the supply of pulverized coals. 

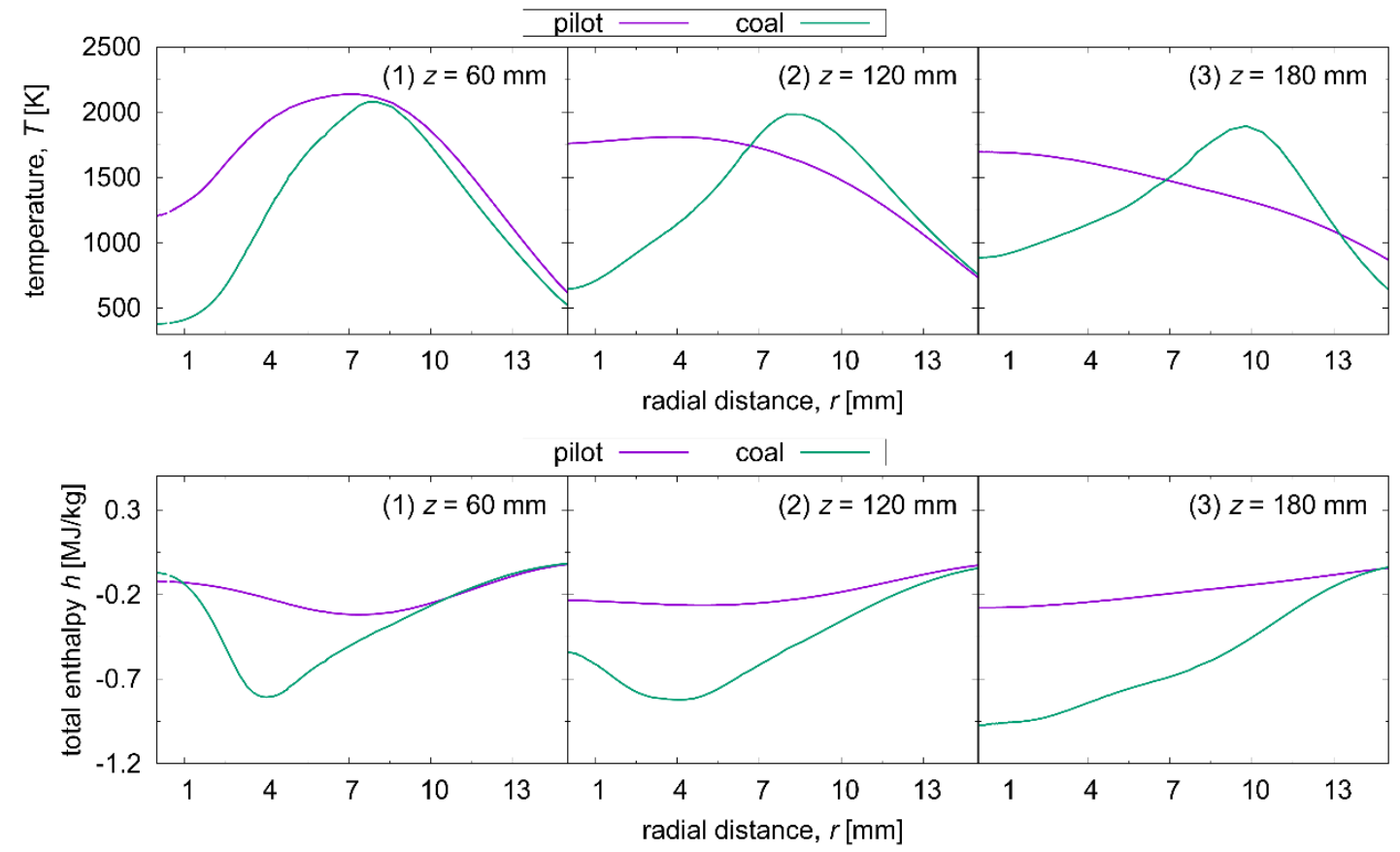

Figure 18 Radial distributions of the time-averaged gas temperature and total enthalpy on the centerline before and after the supply of pulverized coals.

\subsubsection{Combustion mode}

To understand the combustion characteristics of the fuel stream, the flame index ( $\uparrow \mathrm{d}_{d} d_{0}[67]$ was introduced in a normalized form,

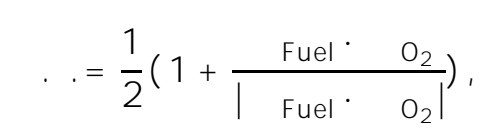

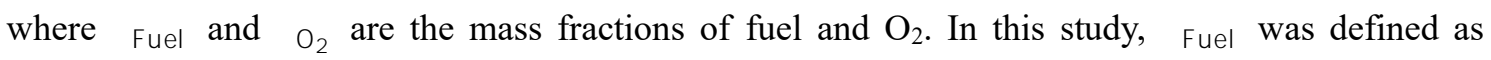

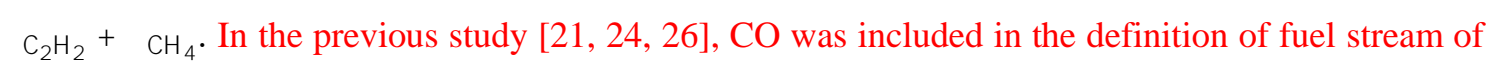
pulverized coal flame. However, $\mathrm{CO}$ was also generated as an intermediate species and $\dagger \mathrm{d}_{0}^{\mathrm{d}} \mathrm{d}$ analysis can result in misinterpretations of the flame mode. Thus, $\mathrm{CO}$ was not included in the definition of fuel gas when $† \mathrm{~d}_{0} d \mathrm{~d}$ was evaluated. The effect of $\mathrm{CO}$ on the $† \mathrm{~d}_{0} \mathrm{~d}_{\mathrm{d}}$ analysis was written in the Appendix.

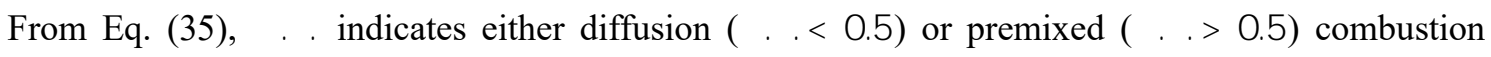
regions by the relationship between the gradients of the fuel and oxidant. To ensure that $†$ d did not

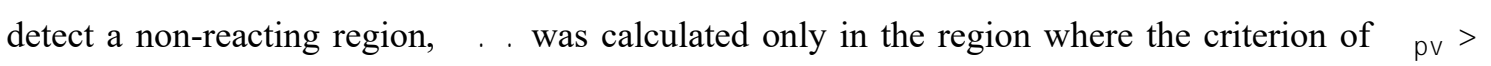
范数通

As another indicator of flame mode, a chemical explosive mode analysis (CEMA) was developed [68] and applied to the counter-flow diffusion flame of pulverized coals by Messig et al. [69]. Although the CEMA would corroborate the results of FI analysis, it was beyond the scope of this study and not performed. 
Figure 19 shows the distributions of the instantaneous, mean, and RMS of the normalized flame index of the pilot flame. An isocontour of the mixture fraction at the stoichiometric conditions of volatile ${ }^{\dagger}$ ๆo $\left.\mathrm{d} \mathrm{d}_{\mathrm{O}}\right)$ is also displayed as black lines in the instantaneous and mean profiles. Both profiles indicate that the layer structure was formed at the upstream side, and two types of reacting zones exist in the inner and outer regions. The outer reacting zone was generated upon the combustion of pilot gas and co-flowing air, and the combustion mode was characterized as diffusion because the gradient of pilot gas turned in the direction opposite to that of the oxidant. Conversely, the inner one was formed upon the combustion of pilot gas with oxidant supplied from the central jet. The isocontour of the mixture fraction suggests that the outer and inner reacting zones were located on the fuel-lean and -rich side of the flame, respectively. Further downstream at $z=60 \mathrm{~mm}$, these two reacting zones encountered and merged into one large reacting zone because the pilot gas supplied from the outer nozzle diffused and was consumed. The RMS values of $†$ d d increased at the junction of two reacting zones, suggesting that the combustion mode within the flame changes in time. Even further downstream, high- $\uparrow \mathrm{d}$ d greater than 0.5 was observed locally in the instantaneous distributions. As the turbulence was developed in this region, the combustion mode within the flame changed locally according to the flow field.

The inner reacting region disappeared at $z=150 \mathrm{~mm}$, and the $† \Phi$ d was calculated only at the edge of the outer reacting region. However, the mass fraction of fuel was less than $\kappa_{d}{ }^{2}{ }^{2} l^{p}{ }^{e} \%$ in

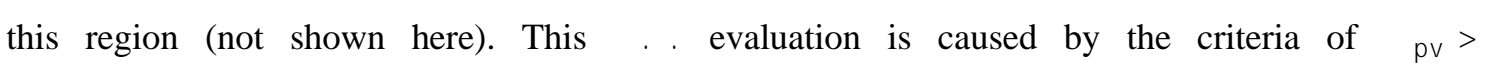

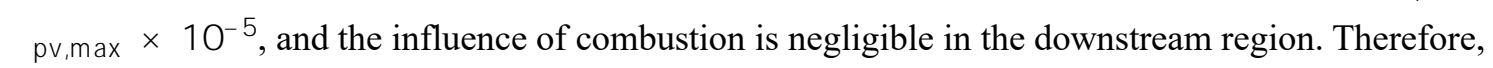
no further evaluation was performed in this area for a pilot flame. 

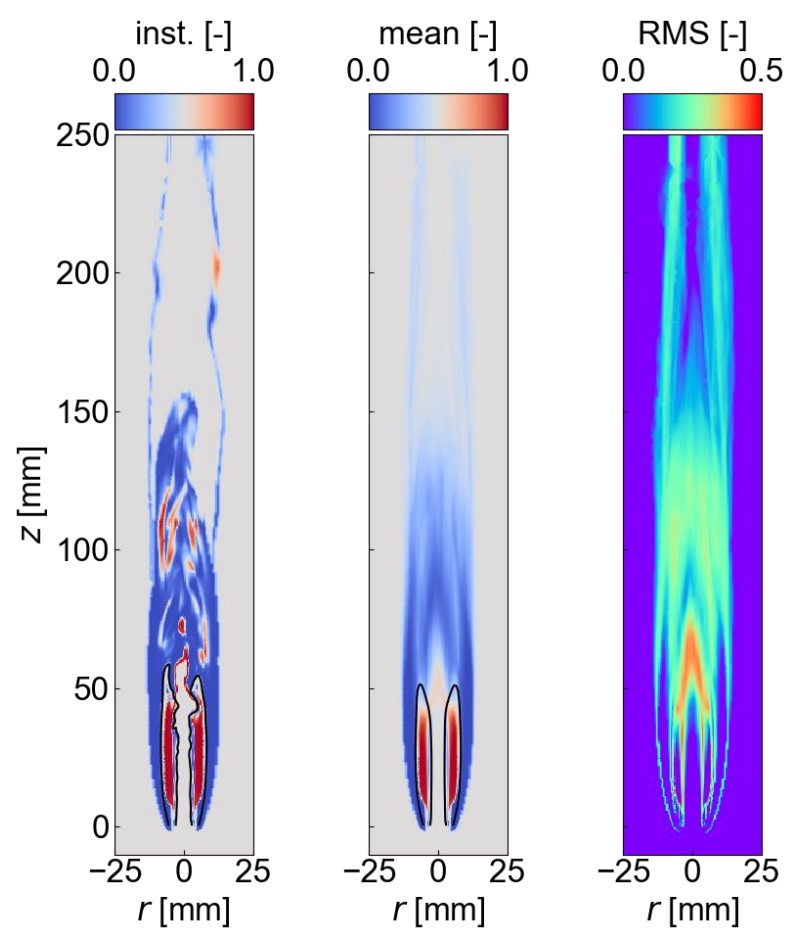

Figure 19 Distributions of the instantaneous, mean, and RMS of the normalized flame index of the pilot flame. The black lines in the instantaneous and mean profiles correspond to the isocontour of the mixture fraction at the stoichiometric mixture of the volatile, ${ }^{\dagger}$ qo $\left.\mathrm{l} \mathrm{d} \varsigma \mathrm{o}\right)$.

Figure 20 shows the radial distributions of the time-averaged major species and production rate of progress variable (PV) at $z=10$ and $55 \mathrm{~mm}$. The axial distances correspond to the positions before and after the junction of the layers, and only the half radial region is shown because of the nearly axisymmetric distribution of the time-averaged mass fractions. The peak of the fuel gas (not including $\mathrm{CO}$ ) was observed at $r=3 \mathrm{~mm}$, where the pilot nozzle was located, and decreases inward and outward. Focusing on the innermost diffusion layer, the gradient turned in the opposite direction to that of the oxidant, and † d w was below 0.5. Conversely, both gradients were in the same direction at slightly larger radii than that of the peak, resulting in $\dagger \mathrm{d} d$ greater than 0.5 . Further, in the outer reaction zone, the gradients of the fuel and co-flow-derived oxygen turned in the opposite direction again, and the $\dagger \mathrm{d}[\mathrm{d}$ became 0.5 or less. This upstream three-layer structure (diffusion $\rightarrow$ premixed $\rightarrow$ diffusion from the inner side) was also reported in a previous DNS of the coal flame by Hara et al. [26]. They considered that the former two layers were owing to the combustion of the volatile and carrier gases, and the later one was owing to the combustion of the pilot gas and co-flowing air. However, the three-layer structure is formed even in the pure pilot flame, i.e., innermost diffusion and premixed layers near the burner can be formed upon the combustion of the pilot gas (not volatile gas) and carrier gas. Considering that Hara et al. focuses 
on the three-layer structure at $z=60 \mathrm{~mm}$, the formation mechanism of the three-layer structure depends on the axial distance.

The upstream two reaction zones were merged into one large reaction zone at $z=55 \mathrm{~mm}$. The fuel was almost consumed, and excess $\mathrm{O}_{2}$ was present. The peak shift of the production rate of PV indicates that the combustion region moved to the center of the flame. Subsequently, premixed combustion occurred because the fuel was preferentially consumed at the boundary layer of the two jets, and its gradient turned in the same direction as that of carrier-gas-derived $\mathrm{O}_{2}$. Thus, the three-layer structure, which was considered to be derived from volatile matter, exists even without pulverized coals.

(a) $z=10 \mathrm{~mm}$

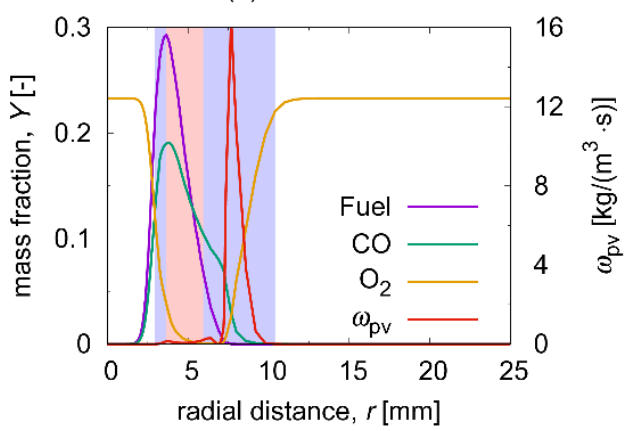

(b) $z=55 \mathrm{~mm}$

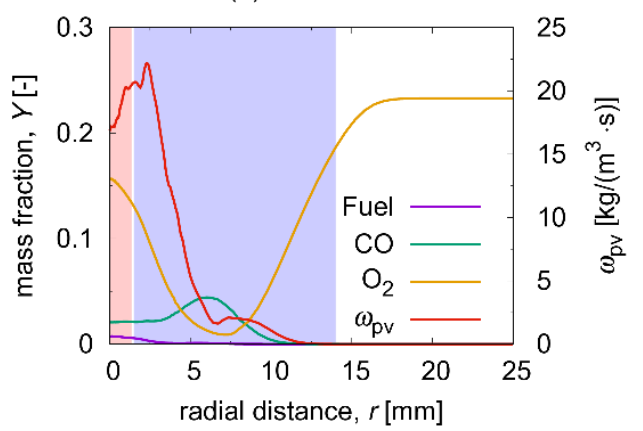

Figure 20 Radial distributions of the time-averaged major species and production rate of $\mathrm{PV}$ at $z=$

10 and $55 \mathrm{~mm}$. The background colors of blue and red represent the diffusion and premixed combustion regions categorized by $\dagger \mathrm{d}$ d r respectively.

Figure 21 shows the distributions of the instantaneous, mean and RMS of the normalized flame index of the coal flame. The three-layer structures can be observed above the pilot nozzle as seen in the pilot flame. Because the width of each combustion region is similar to that in the pilot flame, this threelayer structure should also be generated upon the pilot gas combustion. Moving downstream near $z=$ $75 \mathrm{~mm}$, the premixed combustion region shifted to the outer edge of the flame, and the width decreased, as is recognized in the time-averaged distribution. Hara et al. [26] reported that the combustion of volatile matter with $\mathrm{O}_{2}$ in coal-carrier air occurs in the premixed layer at $z=60 \mathrm{~mm}$. Therefore, the change in the location and width of the premixed layer would indicate the transition of the main sources of fuel gas from pilot gas to volatile matter.

The premixed area in the middle region was locally generated and not stable, whereas it seems to be stable in the DNS. The criteria of $† d_{0}$ d evaluations may be related to the difference from the DNS in addition to the grid resolution. The $† \mathrm{~d}$ d w was evaluated only in the region where the criterion

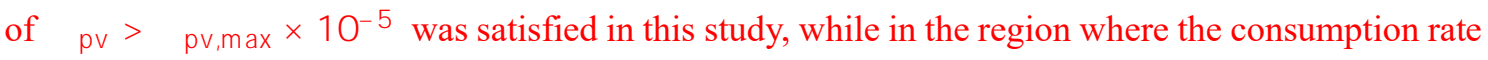
of $\mathrm{O}_{2}$ exceeds $0.05 \mathrm{~s}^{-1}$ in the DNS. Although combustion modeling is also different from the DNS, 
the effects of combustion modeling on $†$ d d distributions are small because the major species profiles agreed with those in the DNS.

The high-RMS region is extended to the inside of the premixed layer near $z=75 \mathrm{~mm}$, while the RMS value is high only at the edge of the reacting layers near $z=10 \mathrm{~mm}$. Although the instantaneous † d d near $z=180 \mathrm{~mm}$ suggests that premixed combustion occurs inside the flame, this region is categorized diffusion or a non-reacting region and cannot be recognized in the time-averaged distribution, implying the combustion mode of volatile matter frequently changes because the RMS value is also high in this region.
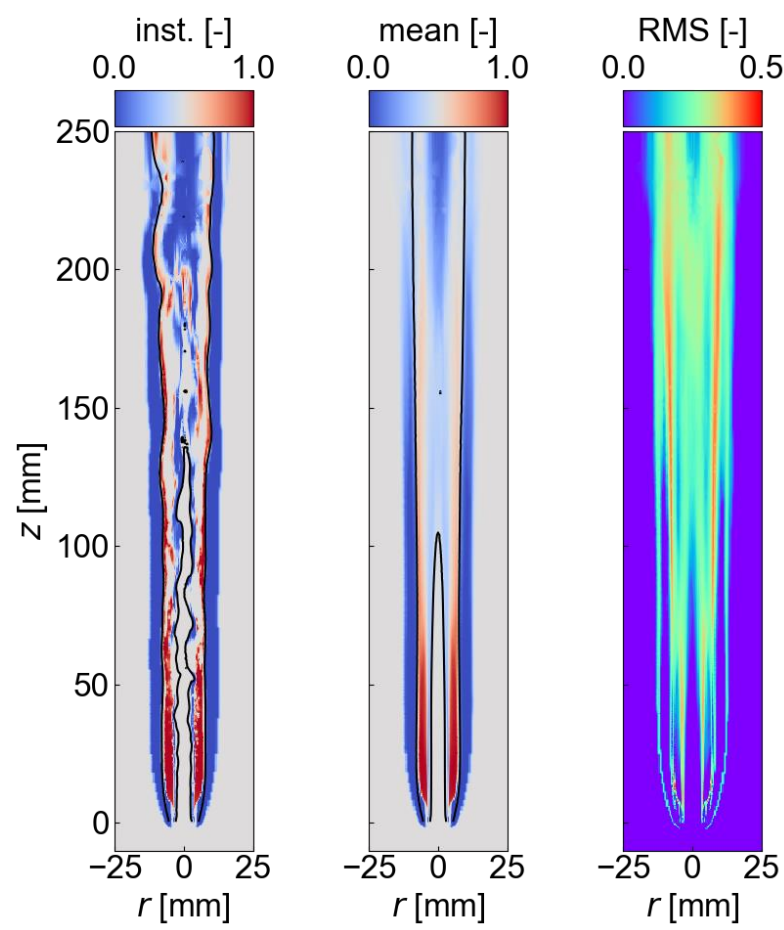

Figure 21 Distributions of the instantaneous, mean, and RMS of the normalized flame index of the coal flame. The black lines in the instantaneous and mean profiles correspond to the isocontour of the mixture fraction at the stoichiometric mixture of volatile $t^{t}$ qo $\mathrm{l}$ d ऽo).

Figure 22 shows the radial distributions of the time-averaged major species at $z=10,100$, and $180 \mathrm{~mm}$. First, the distribution at $z=10 \mathrm{~mm}$ is similar to that of the pilot flame, indicating that the effect of pulverized coals is small in the upstream region. Although the distribution of the chemical species and the generation rate of PV changed considerably from $z=10$ to $z=55 \mathrm{~mm}$ in the pilot flame, the change was minimal from $z=10$ to $z=100 \mathrm{~mm}$ in the coal flame. Then, the inner and outer reacting regions did not merge owing to the effects of heat loss on the gas phase. As fuel release from the pulverized coals increases the mass fraction of fuel in the downstream region, it remains high at $z$ $=100 \mathrm{~mm}$ and $180 \mathrm{~mm}$. This is one of the large differences in the case of the pilot flame, and combustion occurs in the downstream region in the coal flame. $\mathrm{CO}$ is generated as an intermediate 
species, while the fuel is only consumed in combustion, resulting in a mass fraction of CO slightly higher than that of fuel.

(a) $z=10 \mathrm{~mm}$

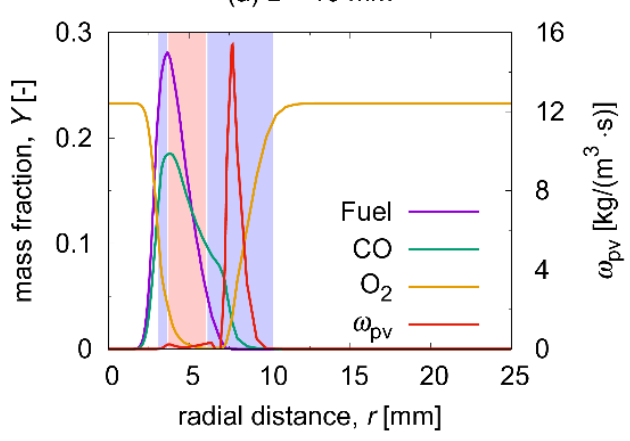

(b) $z=100 \mathrm{~mm}$

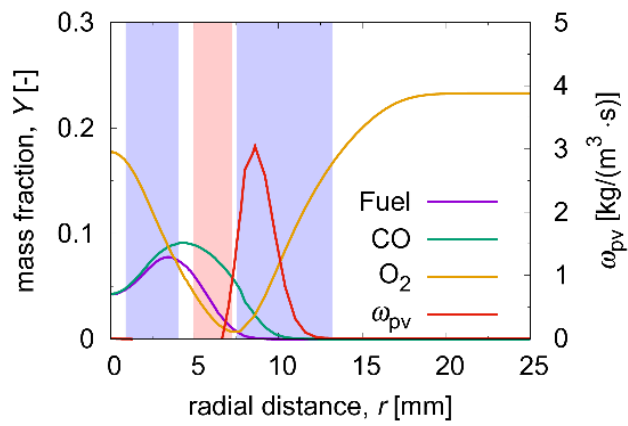

(c) $z=180 \mathrm{~mm}$

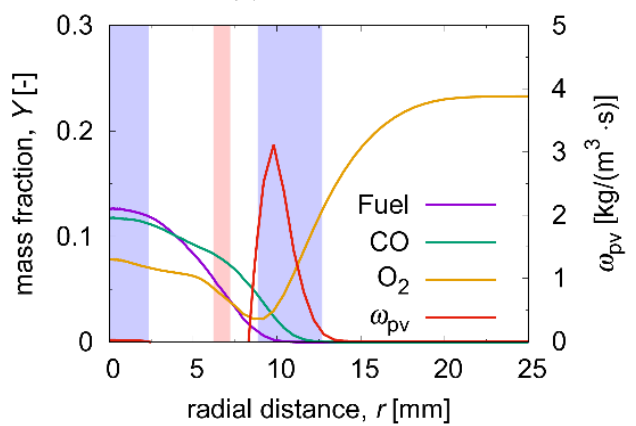

Figure 22 Radial distributions of time-averaged major species at $z=10,100$, and $180 \mathrm{~mm}$. The background colors of blue and red represent the diffusion and premixed combustion regions categorized by $\dagger$ đd respectively.

\subsection{Comparison of temperature and axial velocity between the gas and particle phases}

Figure 23 shows the contour plots of the time-averaged temperature of gas, particles, and their difference, $\breve{T}_{\Omega}^{N} \breve{\Gamma}$ ). The dispersed-phase data are time-averaged values of number-averaged values weighted by the parcel number at each time step becoming zero in a computational cell where no particle exists. The particle temperature elevation began with the particles passing through the pilot gas combustion regions. The high-temperature region of the dispersed phase spread in the radial direction downstream because the particles dispersed to the radial direction by turbulence. The difference became large positive values in the downstream region. This area spread radially in the downstream region; therefore, the difference would be generated by passing the hot particles through the low-temperature region. The distributions of the temperature differences were not the symmetry in the downstream region owing to the problems of statistical convergence as described in previous sections. 
Figure 24 shows the contour plots of the time-averaged axial velocities of gas, particles, and the difference between the two phases, e ${ }^{\circ} \Lambda^{N} \circ \dot{f}$. In this paragraph, the impact of gaseous combustion on the gas and particle velocities is discussed on the basis of the Stokes number calculated in a previous DNS study [26]. The velocity difference is positive at the shear layer in the upstream region. According to the previous DNS study, the Stokes numbers exceeded unity irrespective of the particle diameters, indicating that the particle inertia was dominant in this region. The particles were dispersed while maintaining the momentum provided by the central jet and passed through the shear layers where the gas velocity began to decrease owing to the turbulent viscosity. A positive value of $e^{\circ} \Omega^{N} \circ \dot{f}$ was also observed in the downstream region. The time-averaged diameter in this area was large owing to the large particles. The Stokes number of the particles, which have large initial diameters, exceeded unity even in the downstream region [26], and the explanations in this study are consistent with the previous results.

Figure 25 shows the relationships of the time-averaged temperature and axial velocity between the gas and dispersed phases. The plots are colored by the time-mean particle diameters at each computational cell. In the temperature distribution, the dispersed phase temperature is lower than that of the gas phase, and the difference increases with increasing particle diameter because of large heat capacities. In contrast, a portion of particle temperature is higher than the gas temperature because high-temperature particles, which have large inertia, passed through the low-temperature region. The axial velocity of the dispersed phase is slightly higher than that of the gas phase irrespective of the particle diameter. As shown in Figure 24, a positive relative velocity is obtained near the boundary region between the jet and surrounding air. This result can be explained by relatively large Stokes numbers of the particle because the velocity difference between the gas and particles tends to be large when the time-averaged particle diameter is large. 


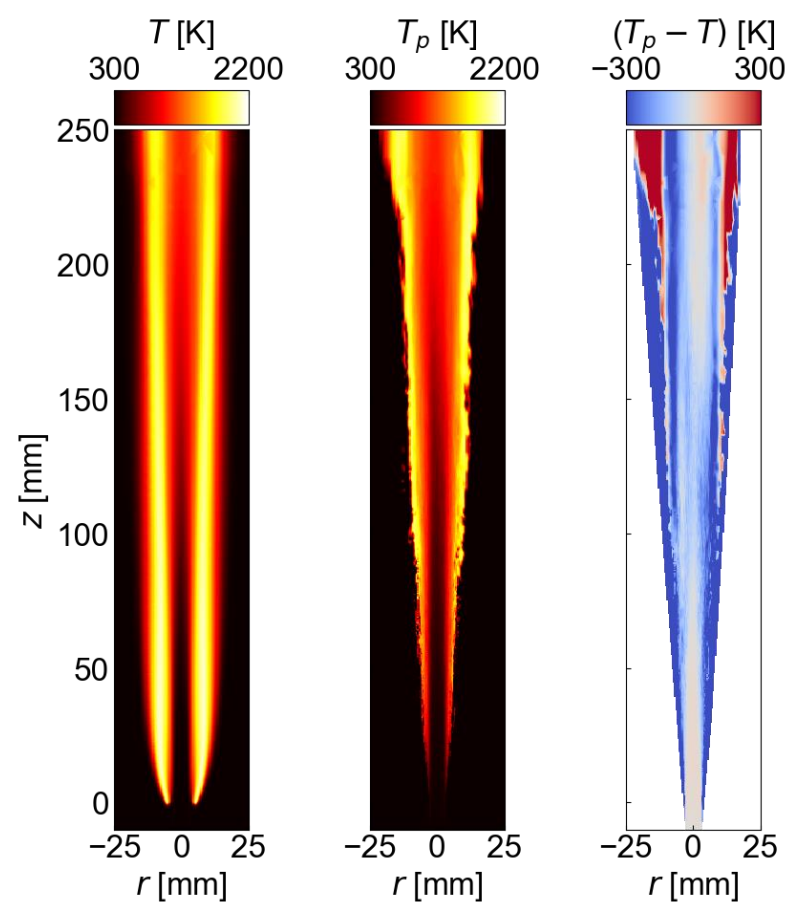

Figure 23 Contour plots of the time-averaged temperature of gas, particles, and their difference.

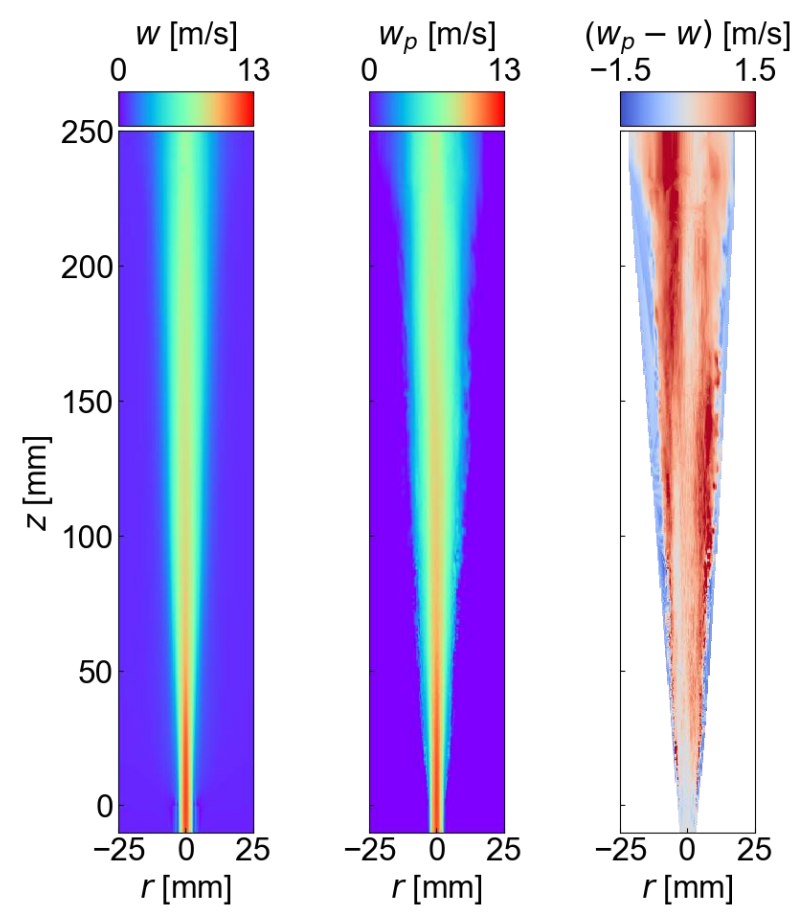

Figure 24 Contour plots of the time-averaged axial velocities of gas, particles, and their difference. 

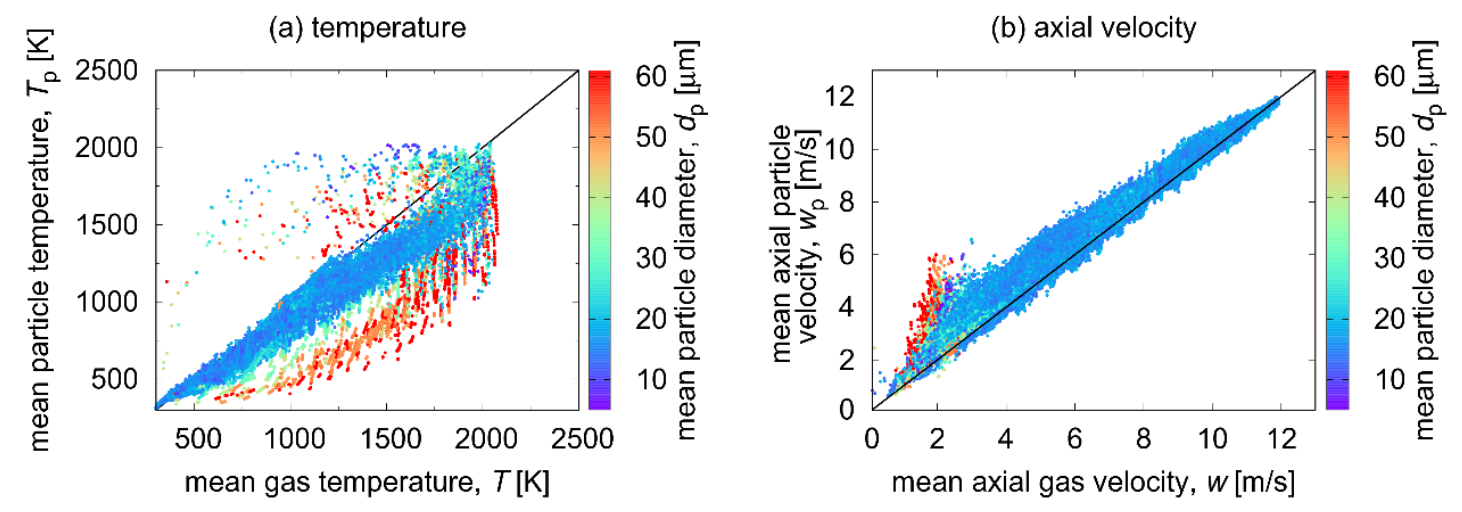

Figure 25 Relationships of the time-averaged temperature and axial velocity between the gas and dispersed phases. The color indicates the mean particle diameters in the Eulerian computational grid.

\section{Conclusion}

The FPV approach was evaluated in the LES of a laboratory-scale pulverized coal jet flame, and the combustion behaviors of the gas and dispersed phases were investigated through simulation. The look-up tables used in the FPV approach were four-dimensional with the sum of the volatile and charoff gas mixture fractions $\left(\dagger^{\dagger}\right)$, char-off gas ratio $\left(\dagger_{\eta t}\right)$, normalized enthalpy $\underbrace{}_{t_{\mathrm{r}} \mathrm{GZ} \theta})$, and normalized progress variable (स). In addition, the mixture fraction variance was considered using the presumed PDF approach on the basis of a top-hat function. First, the distributions of the representative parameters were determined, and the validity of the look-up tables was evaluated in terms of heat loss. Subsequently, the LES represented the particle motion difference between non-reacting and reacting flows. The LES underestimated the measured [14] particle velocity in the outer radial direction, whereas the numerical solution was in agreement with the experiment near the centerline. The underestimation of axial velocity in the outer side was also reported in a previous study and can be related to the influence of limited particle sampling numbers and experimental uncertainties. The numerical solutions were in agreement with the experimental values in the $\mathrm{O}_{2}$ volume fraction, whereas the EBU-derived solutions considerably underestimated the experimental value in a previous study [3]. This is because the look-up tables included information regarding chemical kinematics.

The comparison of the LES results before and after adding the coals indicates the significant impact of the coals on the combustion behaviors through heat loss. As considerable heat loss was observed in the high-temperature region, the heat exchanges between the gas and particles via convective heat transfer were dominant in this study. The flame index suggested that the premixed and diffusion combustion modes coexisted before coal supply. The difference in the flame structure before and after coal supply increases in the downstream side, even though it is small in the upstream region. This is because of the transition of the main sources of the fuel gas from the pilot gas to the volatile 
matter released from the coal. In addition, a comparison of the time-averaged temperature between the gas and dispersed phases indicated that the particle temperature was lower than that in the gas phase, and the difference increased with increasing particle diameters. The particle velocity was slightly higher than that in the gas phase because of the large inertia of the particles. The effect of pulverized coal on the flame structures obtained from this study is believed to be consistent with that of other pulverized coal flames. Therefore, the knowledge obtained from this study is advantageous for the design or optimization of next-generation technologies of pulverized coal combustion.

\section{Acknowledgments}

The authors gratefully acknowledge the Grant-in-Aid for the Japan Society for the Promotion of Science (JSPS) Research Fellow [grant number 18J11135]. A portion of the numerical results in this research was obtained using the supercomputing resources at the Cyberscience Center, Tohoku University.

\section{Appendix}

\section{A.1. Accuracy of look-up tables for small $Z_{2}$ value}

Because the thermal and chemical quantities in the range of $\mathrm{\iota}$ a $t^{t} \mathrm{r}_{\circ}^{\mathrm{a}} \mathrm{\iota}$ d were retrieved using

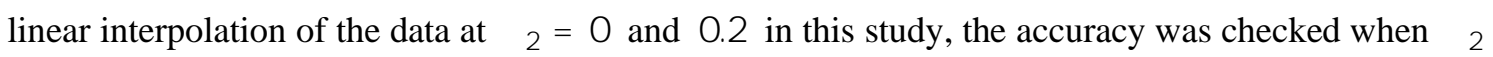
was small. Figure A- 1 shows the dependence of the maximum temperature on $\nearrow{ }_{\pi}$ in the flamelet calculations with FlameMaster. The scalar dissipation rate was set to $4.5 \mathrm{~s}^{-1}$, and both boundary temperatures were set to $300 \mathrm{~K}$. The maximum temperatures are approximately linear with ${ }^{t}{ }_{\pi}$ in the

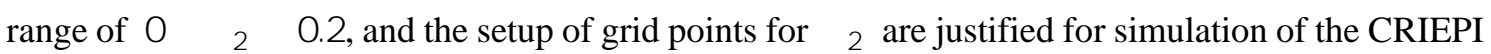
burner. 


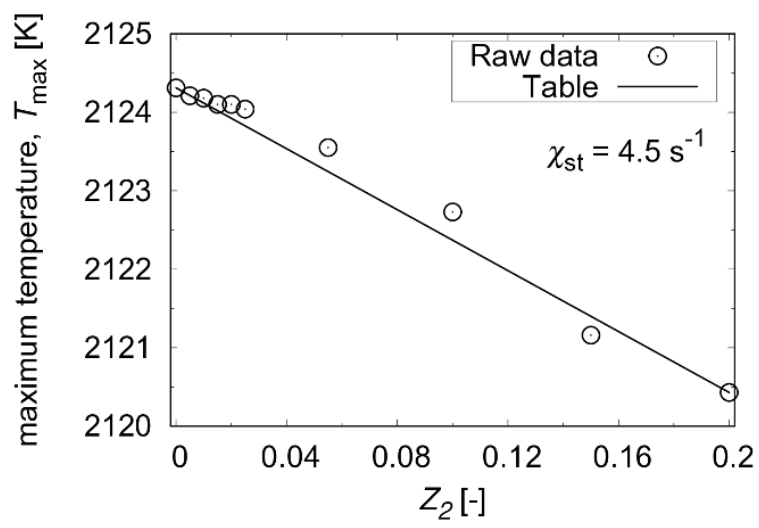

Figure A- 1 Dependence of the maximum temperature on $\nearrow_{n g}$ The boundary temperatures were set to $300 \mathrm{~K}$

\section{A.2 Effects of large hydrocarbons on the temperature and major species profile}

Table A- 1 shows the details of a test calculation. The one-dimensional simulation of the counter-flow diffusion flame was performed using FlameMaster [50]. The boundary temperatures were set to 300 $\mathrm{K}$, and reference fuel composition was the same as the volatile matter in the LES-FPV. The fuel components to be compared were prepared by replacing $\mathrm{C}_{2} \mathrm{H}_{2}$ to $\mathrm{C}_{6} \mathrm{H}_{6}$. Figure A- 2 shows the temperature and major species distributions. The temperature and major species distributions with $\mathrm{C}_{6} \mathrm{H}_{6}$ agreed well to those with $\mathrm{C}_{2} \mathrm{H}_{2}$ except for $\mathrm{H}_{2}$, indicating that the influence of replacement of tar by $\mathrm{C}_{2} \mathrm{H}_{2}$ is much small.

Table A- 1 Details of a test calculation.

\begin{tabular}{|c|c|c|}
\hline code & & FlameMaster [50] \\
\hline computational domain & & one-dimensional counter-flow diffusion flame \\
\hline reaction mechanism & & KM2 [70] \\
\hline stoichiometric scalar dissipation rate & {$[1 / \mathrm{s}]$} & 4.5 \\
\hline fuel temperature & {$[\mathrm{K}]$} & 300 \\
\hline oxidizer temperature & {$[\mathrm{K}]$} & 300 \\
\hline fuel component & {$[-]$} & 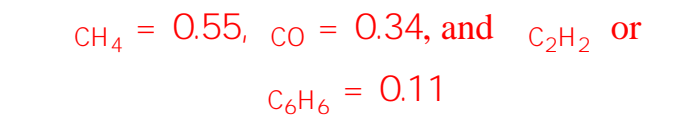 \\
\hline oxidizer component & {$[-]$} & 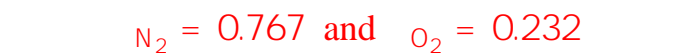 \\
\hline
\end{tabular}




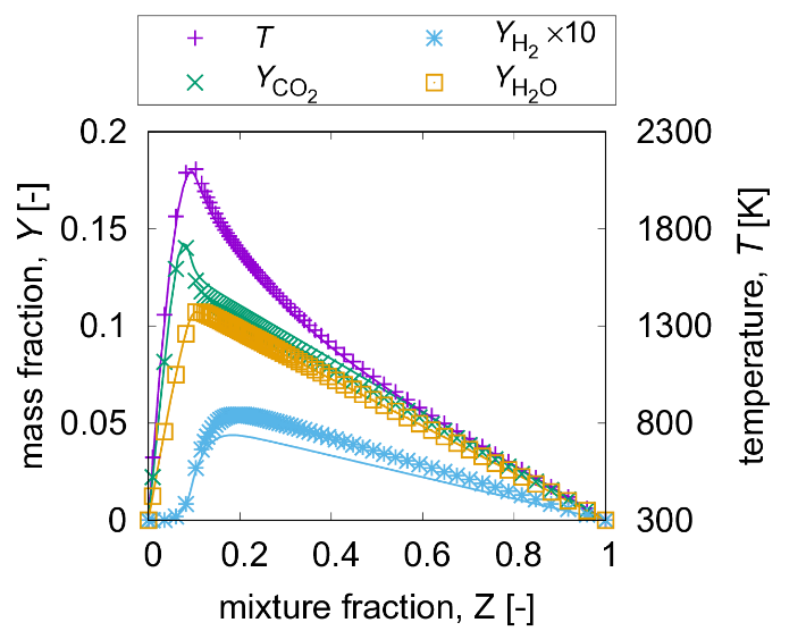

Figure A- 2 Effect of tar species $\left(\mathrm{C}_{6} \mathrm{H}_{6}\right)$ on the temperature and major species distributions. The plots and lines refer to the solutions with $\mathrm{C}_{2} \mathrm{H}_{2}$ and $\mathrm{C}_{6} \mathrm{H}_{6}$, respectively.

\section{A.3 Sensitivity of particle statistics to the sampling period}

The CBC workshop reported that the particle statistics, especially the RMS values, were sensitive to the sampling period in the downstream side and recommended at least $0.35 \mathrm{~s}$ for sampling operations. However, we could not perform this long calculation owing to limited computer resources and stopped sampling the data after confirming that the time-averaged distributions of the fluid properties were approximately symmetric. Then, the sampling period was $0.1 \mathrm{~s}$. To assess the sensitivity of the LES statistics to sampling time, the mean and RMS values of the axial particle velocities obtained from different sampling periods were compared. Figure A- 3 shows the particle statistics from different lengths of sampling periods in axial and radial directions. The sampling periods of $0.05 \mathrm{~s}$ and $0.15 \mathrm{~s}$, i.e., $0.05 \mathrm{~s}$ before and after $0.1 \mathrm{~s}$, were selected in addition to $0.1 \mathrm{~s}$. In the axial distributions, the mean and RMS values are insensitive to the sampling periods in the present range. Although a slight difference is observed in the RMS values of the radial distribution, it is still small compared to the deviations between the predicted and experimental values. The sensitivity of the particle statistics to the sampling periods is unclear owing to the limited range of sampling periods in this comparison. 
(a) mean values

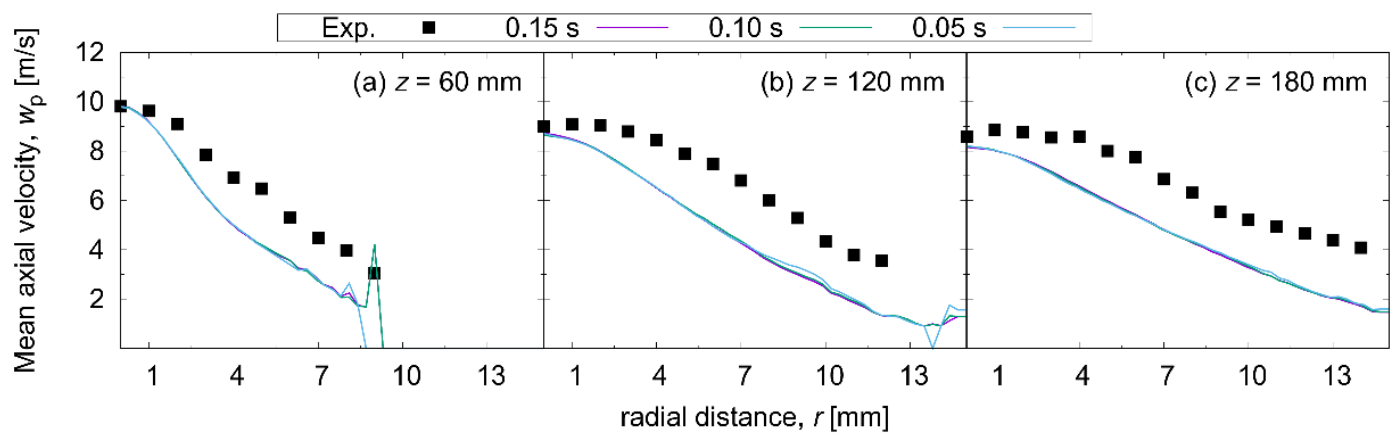

(b) RMS values

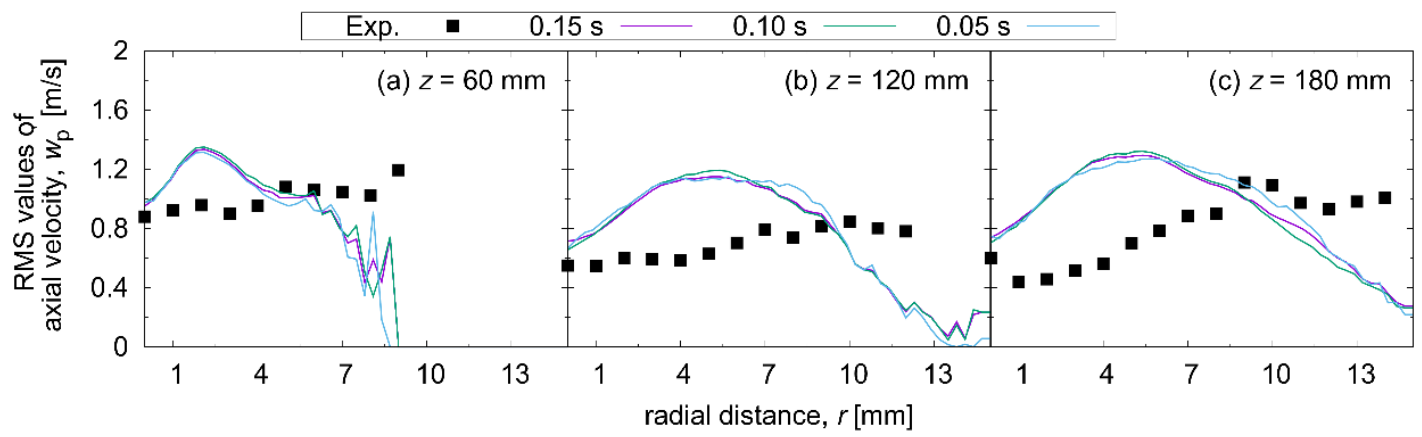

Figure A- 3 Comparison of particle statistics from different lengths of the sampling period in the radial direction.

\section{A.4. Inlet velocity boundary conditions}

The CBC workshop [17] provides the central jet velocity profiles on the inlet planes between $t$ $=0$ and $1.5 \mathrm{~s}$ with time intervals of approximately $\operatorname{odg}_{\mathrm{d}} \rho \varsigma^{2} \mathrm{\kappa l}^{\mathrm{e} \cdot \mathrm{r}} \mathrm{s}$. This data were generated by the inflow generator proposed in [71] and included the turbulent fluctuations in all directions. Figure A-4 shows the grid points and transient data at several grid points. The transient data at five points were extracted and are shown in Figure A-4 (b). The data were tabulated as a coordinate function of

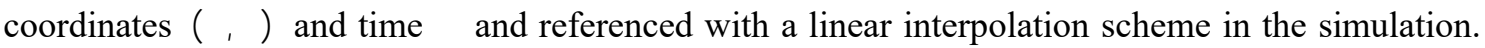
Figure A-5 shows the grid points in the table and a comparison of the interpolated transient data at P5 with original data [17]. The interpolated data captured the variation of the original data. The velocities at all points of the inlet cross-section were given by the interpolations of CBC data. 
(a) grid points (original data)

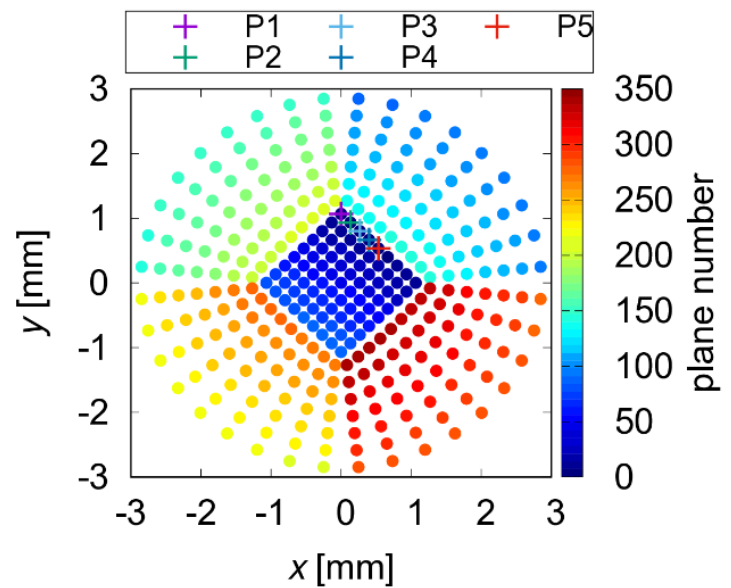

(b) transient data

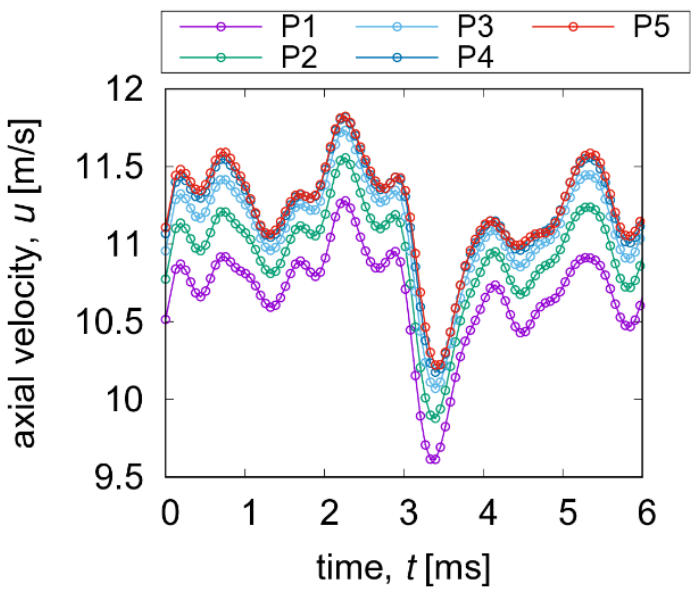

Figure A-4 Grid points and transient data at several sampling points [17]. Cross-shaped symbols in figure (a) indicate the sampling points (P1-P5) for checking the transient axial velocities in figure

(b).

(a) grid points (interpolated data)

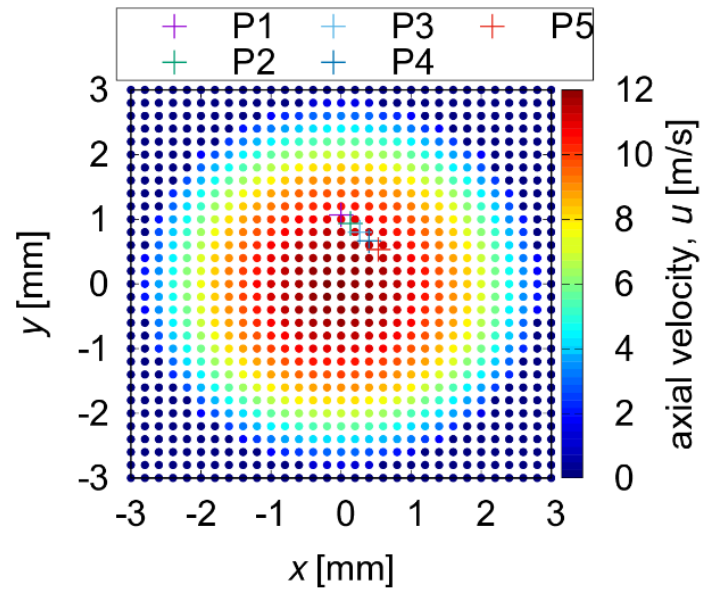

(b) transient data at P5

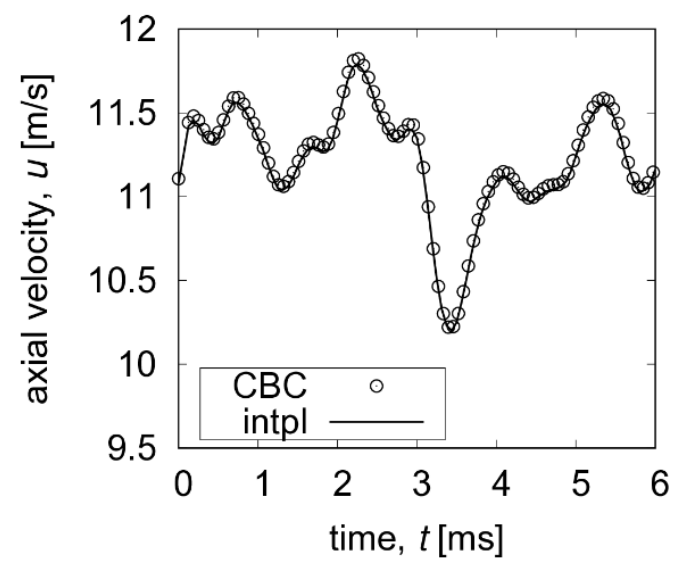

Figure A-5 Grid points in the table and comparison of the interpolated transient data at P5 with original data [17].

\section{A.5. Effect of $\mathrm{CO}$ on the $\mathrm{FI}$ analysis}

The impact of $\mathrm{CO}$ on the $† \mathrm{~d}_{0} \mathrm{~d}$ was investigated in the simulation of a simple counter-flow diffusion flame. The computational domain is the same as that in the previous study [21,23]. Figure A- 6 shows the distributions of two types of $† \mathrm{~d} d \mathrm{~d}$ For explanations, we refer $\dagger \mathrm{d}$ d $\mathrm{d}_{\mathrm{x}}$ with and without $\mathrm{CO}$ to case 1 and case 2 , respectively. In the two types of reaction zones formed on the fuel and oxidizer sides, there was a large difference in the zone on the fuel side. Although it has both premixed and diffusion combustion layers, an additional diffusion combustion layer was formed in case 1 . To identify the cause of the difference, the axial distributions of mass fractions of fuel and oxidizer were shown in Figure A- 7. The locations at $₹=0.0$ and $₹=20 \mathrm{~mm}$ correspond to the lower and upper ports, 
respectively. The mass fraction of fuel gradually increased from $P_{-} \lambda_{\mathrm{l}} \mathrm{mm}$ to $P_{-} \mathrm{l}$ in both cases. However, fuel in case 1 steeply increased at the starting point of the reaction zone, i.e., approximately २ $\kappa \lambda \phi_{6} \mathrm{~mm}$. This sudden increase of the mass fraction of fuel can be explained by $\mathrm{CO}$ as is evident from the figure (b). As the other volatile species, i.e., $\mathrm{CH}_{4}$ and $\mathrm{C}_{2} \mathrm{H}_{2}$, decreased in the reaction zone, the increase of $\mathrm{CO}$ was attributable to the intermediate species. Therefore, it is found that $\dagger \mathrm{d}[\mathrm{d}$ results would become misleading if they include $\mathrm{CO}$ as fuel gas. Based on the above test, we decided to use only $\mathrm{CH}_{4}$ and $\mathrm{C}_{2} \mathrm{H}_{2}$ as fuel gas and exclude $\mathrm{CO}$ in the $†$ d d d evaluation in this study.

(a) Case 1 (with CO)

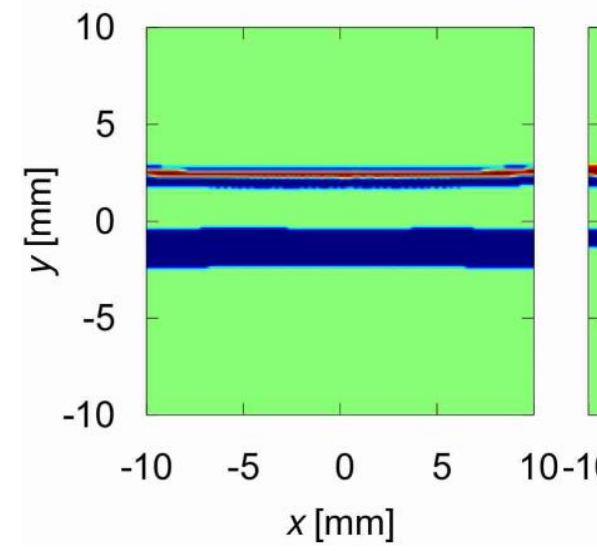

(b) Case 2 (without CO)

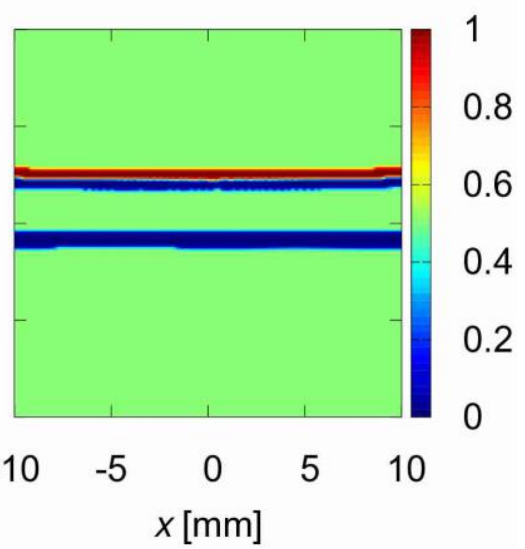

Figure A- 6 Effects of $\mathrm{CO}$ inclusion in the fuel gas on the normalized flame index. The domain is a counter-flow diffusion flame of pulverized coals used in previous works [21, 23].

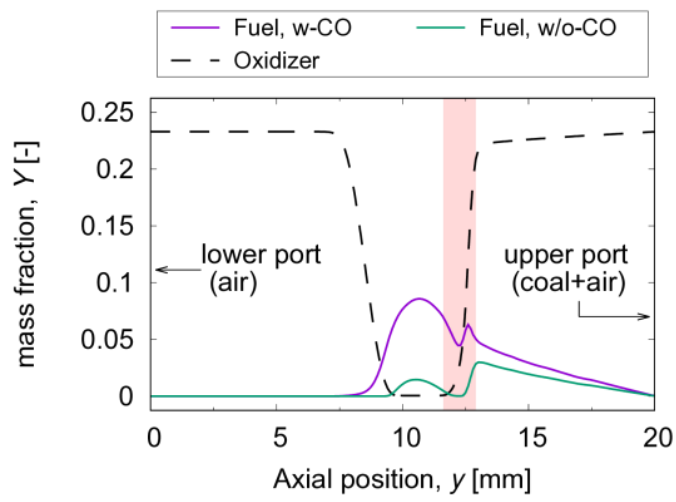

(a) fuel and oxidizer

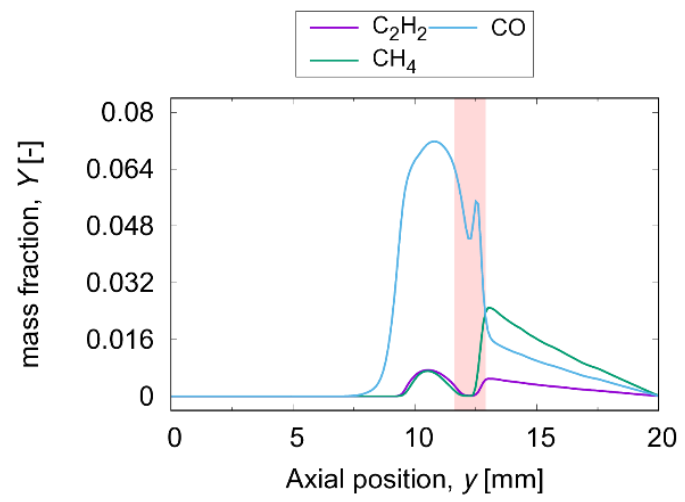

(b) species in the fuel

Figure A- 7 Axial distributions of mass fractions of fuel and oxidizer streams. The red color means the reaction zone at the fuel side.

\section{References}

[1] The U.S. Energy Information Administration (EIA), International Energy Outlook 2019, https://www.eia.gov/ieo

[2] K. Yamamoto, T. Murota, T. Okazaki, M. Taniguchi, Large eddy simulation of a pulverized coal jet flame ignited by a preheated gas flow, Proc. Combust. Inst. 33 (2011) 1771-1778. http://dx.doi.org/10.1016/j.proci.2010.05.113. 
[3] B.M. Franchetti, F. Cavallo Marincola, S. Navarro-Martinez, A.M. Kempf, Large Eddy simulation of a pulverised coal jet flame, Proc. Combust. Inst. 34 (2013) 2419-2426. http://dx.doi.org/10.1016/j.proci.2012.07.056.

[4] M. Rabaçal, B.M. Franchetti, F.C. Marincola, F. Proch, M. Costa, C. Hasse, A.M. Kempf, Large Eddy Simulation of coal combustion in a large-scale laboratory furnace, Proc. Combust. Inst. 35 (2015) 36093617. http://dx.doi.org/10.1016/j.proci.2014.06.023.

[5] M. Muto, H. Watanabe, R. Kurose, S. Komori, S. Balusamy, S. Hochgreb, Large-eddy simulation of pulverized coal jet flame - Effect of oxygen concentration on NOx formation, Fuel 142 (2015) 152-163. http://dx.doi.org/10.1016/j.fuel.2014.10.069.

[6] P.E. DesJardin, S.H. Frankel, Large eddy simulation of a nonpremixed reacting jet: Application and assessment of subgrid-scale combustion models, Phys. Fluids 10 (1998) 2298-2314. http://dx.doi.org/10.1063/1.869749.

[7] M. Rieth, F. Proch, M. Rabaçal, B.M. Franchetti, F. Cavallo Marincola, A.M. Kempf, Flamelet LES of a semi-industrial pulverized coal furnace, Combust. Flame 173 (2016) 39-56. http://dx.doi.org/10.1016/j.combustflame.2016.07.013.

[8] X. Wen, K. Luo, Y. Luo, H.I. Kassem, H. Jin, J. Fan, Large eddy simulation of a semi-industrial scale coal furnace using non-adiabatic three-stream flamelet/progress variable model, Applied Energy 183 (2016) 1086-1097. https://doi.org/10.1016/j.apenergy.2016.09.034.

[9] J. Watanabe, K. Yamamoto, Flamelet model for pulverized coal combustion, Proc. Combust. Inst. 35 (2015) 2315-2322. http://dx.doi.org/10.1016/j.proci.2014.07.065.

[10] J. Watanabe, T. Okazaki, K. Yamamoto, K. Kuramashi, A. Baba, Large-eddy simulation of pulverized coal combustion using flamelet model, Proc. Combust. Inst. 36 (2017) 2155-2163. http://dx.doi.org/10.1016/i.proci.2016.06.031.

[11] X. Wen, Y. Luo, K. Luo, H. Jin, J. Fan, LES of pulverized coal combustion with a multi-regime flamelet model, Fuel 188 (2017) 661-671. http://dx.doi.org/10.1016/j.fuel.2016.10.070.

[12] M. Rieth, F. Proch, A.G. Clements, M. Rabaçal, A.M. Kempf, Highly resolved flamelet LES of a semiindustrial scale coal furnace, Proc. Combust. Inst. $36 \quad$ (2017) 3371-3379. https://doi.org/10.1016/j.proci.2016.08.089.

[13] C.D. PIERCE, P. MOIN, Progress-variable approach for large-eddy simulation of non-premixed turbulent combustion, J. Fluid Mech. 504 (2004) 73-97. http://dx.doi.org/10.1017/S0022112004008213.

[14] S.-M. Hwang, R. Kurose, F. Akamatsu, H. Tsuji, H. Makino, M. Katsuki, Application of Optical Diagnostics Techniques to a Laboratory-Scale Turbulent Pulverized Coal Flame, Energy Fuels 19 (2005) 382-392. http://dx.doi.org/10.1021/ef049867z.

[15] N. Hashimoto, R. Kurose, H. Shirai, Numerical simulation of pulverized coal jet flame employing the TDP model, Fuel 97 (2012) 277-287. http://dx.doi.org/10.1016/i.fuel.2012.03.005.

[16] A. Bermúdez, J.L. Ferrín, A. Liñán, L. Saavedra, Numerical simulation of group combustion of 
$\begin{array}{llllll}\text { pulverized } & \text { coal, } & \text { Combust. } & \text { Flame } & 158 & \text { (2011) }\end{array}$ http://dx.doi.org/10.1016/j.combustflame.2011.02.002.

[17] Christian Hasse, Andreas Kempf, Andreas Kronenburg, Kun Luo, Perrine Pepiot, Chris Shaddix, Oliver Stein, Hiroaki Watanabe, Simone Hochgreb, Reinhold Kneer, M. Costa, Coal and Biomass Conversion (CBC) workshop, http://www.cbc.uni-due.de/?file=workshop

[18] O.T. Stein, G. Olenik, A. Kronenburg, F. Cavallo Marincola, B.M. Franchetti, A.M. Kempf, M. Ghiani, M. Vascellari, C. Hasse, Towards Comprehensive Coal Combustion Modelling for LES, Flow, Turbulence and Combustion 90 (2013) 859-884. http://dx.doi.org/10.1007/s10494-012-9423-y.

[19] M. Rieth, A.G. Clements, M. Rabaçal, F. Proch, O.T. Stein, A.M. Kempf, Flamelet LES modeling of coal combustion with detailed devolatilization by directly coupled CPD, Proc. Combust. Inst. 36 (2017) 2181-2189. http://dx.doi.org/10.1016/j.proci.2016.06.077.

[20] S. Ahn, K. Tanno, H. Watanabe, Numerical analysis of particle dispersion and combustion characteristics on a piloted coaxial pulverized coal jet flame, Appl. Therm. Eng. 124 (2017) 1194-1202. https://doi.org/10.1016/j.applthermaleng.2017.06.103.

[21] X. Wen, H. Wang, Y. Luo, K. Luo, J. Fan, Evaluation of flamelet/progress variable model for laminar $\begin{array}{lllllll}\text { pulverized coal combustion, } & \text { Phys. } & \text { Fluids } & 29 & \text { (2017) }\end{array}$ http://aip.scitation.org/doi/abs/10.1063/1.4999335.

[22] X. Wen, J. Fan, Flamelet modeling of laminar pulverized coal combustion with different particle sizes, Adv. Powder Technol. 30 (2019) 2964-2979. https://doi.org/10.1016/j.apt.2019.09.004.

[23] S. Akaotsu, Y. Matsushita, H. Aoki, W. Malalasekera, Analysis of flame structure using detailed chemistry and applicability of flamelet/progress variable model in the laminar counter-flow diffusion flames of pulverized coals, Adv. Powder Technol. $31 \quad$ (2020) 1302-1322. https://doi.org/10.1016/j.apt.2019.12.019.

[24] M. Rieth, A.M. Kempf, A. Kronenburg, O.T. Stein, Carrier-phase DNS of pulverized coal particle ignition and volatile burning in a turbulent mixing layer, Fuel 212 (2018) 364-374. https://doi.org/10.1016/j.fuel.2017.09.096.

[25] M. Rieth, A.M. Kempf, O.T. Stein, A. Kronenburg, C. Hasse, M. Vascellari, Evaluation of a flamelet/progress variable approach for pulverized coal combustion in a turbulent mixing layer, Proc. Combust. Inst. 37 (2019) 2927-2934. https://doi.org/10.1016/j.proci.2018.05.150.

[26] T. Hara, M. Muto, T. Kitano, R. Kurose, S. Komori, Direct numerical simulation of a pulverized coal jet flame employing a global volatile matter reaction scheme based on detailed reaction mechanism, Combust. Flame 162 (2015) 4391-4407. http://dx.doi.org/10.1016/j.combustflame.2015.07.027.

[27] U.P. Massimo Germano, Parviz Moin and William H. Cabot, A dynamic subgrid - scale eddy viscosity model, Physics of Fluids A: Fluid Dynamics (1989-1993) 3 (1991) 1760-1765. http://dx.doi.org/10.1063/1.857955.

[28] X. Wen, K. Luo, H. Jin, J. Fan, Large eddy simulation of piloted pulverised coal combustion using 
extended flamelet/progress variable model, Combust. Theor. Model. 21 (2017) 925-953. https://doi.org/10.1080/13647830.2017.1314552.

[29] C. Pera, J. Réveillon, L. Vervisch, P. Domingo, Modeling subgrid scale mixture fraction variance in LES of evaporating spray, Combust. Flame $146 \quad$ (2006) 635-648. http://dx.doi.org/10.1016/j.combustflame.2006.07.003.

[30] S. De, S.H. Kim, Large eddy simulation of dilute reacting sprays: Droplet evaporation and scalar mixing, Combust. Flame 160 (2013) 2048-2066. https://doi.org/10.1016/j.combustflame.2013.04.024.

[31] A. Rittler, F. Proch, A.M. Kempf, LES of the Sydney piloted spray flame series with the PFGM/ATF approach and different sub-filter models, Combust. Flame 162 (2015) 1575-1598. http://dx.doi.org/10.1016/j.combustflame.2014.11.025.

[32] X. Wen, K. Luo, Y. Luo, H. Wang, J. Fan, Large-eddy simulation of multiphase combustion jet in cross-flow using flamelet model, Int. J. Multiphase Flow 108 (2018) 211-225. https://doi.org/10.1016/j.ijmultiphaseflow.2018.06.017.

[33] Szu-Cheng S. Ou, K.-N. Liou, Generalization of the spherical harmonic method to radiative transfer in multi-dimensional space, J. Quant. Spectrosc. Radiat. Transfer 28 (1982) 271-288. http://dx.doi.org/10.1016/0022-4073(82)90028-0.

[34] P. Cheng, Two-dimensional radiating gas flow by a moment method, AIAA Journal 2 (1964) 1662 1664. https://doi.org/10.2514/3.2645.

[35] C.T. Crowe, M.P. Sharma, D.E. Stock, The Particle-Source-In Cell (PSI-CELL) Model for Gas-Droplet Flows, J. Fluids Eng. 99 (1977) 325-332. http://dx.doi.org/10.1115/1.3448756.

[36] S. Badzioch, P.G.W. Hawksley, Kinetics of Thermal Decomposition of Pulverized Coal Particles, Ind. Eng. Chem. Process Des. Dev. 9 (1970) 521-530. http://dx.doi.org/10.1021/i260036a005.

[37] M.A. Field, Rate of combustion of size-graded fractions of char from a low-rank coal between 1200 K and 2000 K, Combust. Flame 13 (1969) 237-252. http://dx.doi.org/10.1016/0010-2180(69)90002-9.

[38] M. A. Field, D. W. Gill, B. B. Morgan, P.G.W. Hawkslay, Combustion of Pulverized Coal, British Coal Utilization Research Association, Lcatherhead, 1967.

[39] W.P. Jones, S. Lyra, S. Navarro-Martinez, Large Eddy Simulation of a swirl stabilized spray flame, Proc. Combust. Inst. 33 (2011) 2153-2160. http://dx.doi.org/10.1016/j.proci.2010.07.032.

[40] R. Clift, J.R. Grace, M.E. Weber, Bubbles, drops, and particles, Academic Press, New York, 1978.

[41] M. Bini, W.P. Jones, Large-eddy simulation of particle-laden turbulent flows, J. Fluid Mech. 614 (2008)

207-252. https://www.cambridge.org/core/article/largeeddy-simulation-of-particleladen-turbulentflows/64C1B7183847FAF2BBD7A72B9ED39428

https://www.cambridge.org/core/services/aop-cambridgecore/content/view/64C1B7183847FAF2BBD7A72B9ED39428/S0022112008003443a.pdf/div-class-titlelarge-eddy-simulation-of-particle-laden-turbulent-flows-div.pdf.

[42] D. Merrick, Mathematical models of the thermal decomposition of coal: 2. Specific heats and heats of 
reaction, Fuel 62 (1983) 540-546. https://doi.org/10.1016/0016-2361(83)90223-5.

[43] B.S. Brewster, L.L. Baxter, L.D. Smoot, Treatment of coal devolatilization in comprehensive combustion modeling, Energy Fuels 2 (1988) 362-370. http://dx.doi.org/10.1021/ef00010a001.

[44] W.E. Ranz, W.R. Marshall, Evaporation from drops: Part I Chem. Eng. Prog. 48 (1952) 141-146.

[45] L.D. Smoot, D.T. Pratt, Pulverized-coal combustion and gasification, Springer, Boston, MA1979.

[46] M. Stöllinger, B. Naud, D. Roekaerts, N. Beishuizen, S. Heinz, PDF modeling and simulations of pulverized coal combustion - Part 2: Application, Combust. Flame 160 (2013) 396-410. http://dx.doi.org/10.1016/j.combustflame.2012.10.011.

[47] J. McConnell, J.C. Sutherland, Assessment of various tar and soot treatment methods and a priori analysis of the steady laminar flamelet model for use in coal combustion simulation, Fuel 265 (2020) 116775. https://doi.org/10.1016/j.fuel.2019.116775.

[48] B. Goshayeshi, J.C. Sutherland, A comparison of various models in predicting ignition delay in singleparticle coal combustion, Combust. Flame $161 \quad$ (2014) 1900-1910. https://doi.org/10.1016/j.combustflame.2014.01.010.

[49] M. Vascellari, H. Xu, C. Hasse, Flamelet modeling of coal particle ignition, Proc. Combust. Inst. 34 (2013) 2445-2452. http://dx.doi.org/10.1016/j.proci.2012.06.152.

[50] H. Pitsch, A C++ program package for $0 \mathrm{D}$ combustion and 1D laminar flame calculations, http://www.itv.rwth-aachen.de/index.php?id=128

[51] A. Kazakov, M. Frenklach, Reduced Reaction Sets based on GRI-Mech 1.2, http://combustion.berkeley.edu/drm/

[52] X. Wen, H. Wang, Y. Luo, K. Luo, J. Fan, Numerical investigation of the effects of volatile matter composition and chemical reaction mechanism on pulverized coal combustion characteristics, Fuel 210 (2017) 695-704. https://doi.org/10.1016/j.fuel.2017.08.115.

[53] S. Weise, C. Hasse, Reducing the memory footprint in Large Eddy Simulations of reactive flows, Parallel Computing 49 (2015) 50-65. https://doi.org/10.1016/j.parco.2015.07.004.

[54] F. Proch, A.M. Kempf, Modeling heat loss effects in the large eddy simulation of a model gas turbine combustor with premixed flamelet generated manifolds, Proc. Combust. Inst. 35 (2015) 3337-3345. http://dx.doi.org/10.1016/j.proci.2014.07.036.

[55] C. Olbricht, O.T. Stein, J. Janicka, J.A. van Oijen, S. Wysocki, A.M. Kempf, LES of lifted flames in a gas turbine model combustor using top-hat filtered PFGM chemistry, Fuel 96 (2012) 100-107. https://doi.org/10.1016/j.fuel.2012.01.018.

[56] X. Wen, Y. Luo, H. Wang, K. Luo, H. Jin, J. Fan, A three mixture fraction flamelet model for multistream laminar pulverized coal combustion, Proc. Combust. Inst. 37 (2019) 2901-2910. http://www.sciencedirect.com/science/article/pii/S1540748918301536.

[57] J. Floyd, A.M. Kempf, A. Kronenburg, R.H. Ram, A simple model for the filtered density function for passive scalar combustion LES, Combust. Theor. Model. 13 (2009) 559-588. 
http://www.tandfonline.com/doi/abs/10.1080/13647830802632200.

[58] S. Akaotsu, R. Ozawa, Y. Matsushita, H. Aoki, W. Malalasekera, Effects of infinitely fast chemistry on combustion behavior of coaxial diffusion flame predicted by large eddy simulation, Fuel Process. Technol. 199 (2020) 106226. https://doi.org/10.1016/j.fuproc.2019.106226.

[59] P.L. Roe, Some contributions to the modelling of discontinuous flows, Springer-Verlag, Berlin, 1985. [60] A.A. Amsden, F.H. Harlow, A simplified MAC technique for incompressible fluid flow calculations, J. Comput. Phys. 6 (1970) 322-325. http://dx.doi.org/10.1016/0021-9991(70)90029-X.

[61] N. Nomura, A. Fujii, T. Tanaka, O. Marques, K. Nakajima, Algebraic Multigrid Solver Using Coarse Grid Aggregation with Independent Aggregation, IEEE International Parallel and Distributed Processing Symposium Workshops (IPDPSW), 2018

[62] H.A.v.d. Vorst, Bi-CGSTAB: A Fast and Smoothly Converging Variant of Bi-CG for the Solution of Nonsymmetric Linear Systems, SIAM Journal on Scientific and Statistical Computing 13 (1992) 631-644. http://dx.doi.org/10.1137/0913035.

[63] Y. Matsushita, OUTFLOW BOUNDARY CONDITION IN THE FINITE-VOLUME METHOD FOR UNSTEADY-STATE FLUID FLOW COMPUTATION WITH VARIABLE DENSITY, Computational Thermal Sciences 3 (2014) 531-537. http://dx.doi.org/10.1615/ComputThermalScien.2012003330.

[64] S.B. Pope, Ten questions concerning the large-eddy simulation of turbulent flows, New Journal of Physics 6 (2004) 35-35. http://dx.doi.org/10.1088/1367-2630/6/1/035

https://iopscience.iop.org/article/10.1088/1367-2630/6/1/035/pdf.

[65] J.C.R. Hunt, A. Wray, P. Moin, Eddies, stream, and convergence zones in turbulent flows, Center for Turbulence Research, Proceeding of the Summer Program 1988 (1988) 193-208. https://ntrs.nasa.gov/search.jsp?R=19890015184.

[66] L.Y. Hu, L.X. Zhou, J. Zhang, Large-Eddy Simulation of a Swirling Diffusion Flame Using a SOM SGS Combustion Model, Numer. Heat Tr. B: Fund. 50 (2006) 41-58. http://dx.doi.org/10.1080/10407790500459395.

[67] H. Yamashita, M. Shimada, T. Takeno, A numerical study on flame stability at the transition point of jet diffusion flames, Symp. (Int.) Combust. 26 (1996) 27-34. http://dx.doi.org/10.1016/S00820784(96)80196-2.

[68] T.F. Lu, C.S. Yoo, J.H. Chen, C.K. Law, Three-dimensional direct numerical simulation of a turbulent lifted hydrogen jet flame in heated coflow: a chemical explosive mode analysis, J. Fluid Mech. 652 (2010) 45-64. $\quad$ https://www.cambridge.org/core/article/threedimensional-direct-numerical-simulation-of-aturbulent-lifted-hydrogen-jet-flame-in-heated-coflow-a-chemical-explosive-modeanalysis/447BD0E7DA9E1599A9F61786AA62AF79.

[69] D. Messig, M. Vascellari, C. Hasse, Flame structure analysis and flamelet progress variable modelling of strained coal flames, Combust. Theor. Model. 21 (2017) 700-721. https://doi.org/10.1080/13647830.2017.1290279. 
[70] Y. Wang, A. Raj, S.H. Chung, A PAH growth mechanism and synergistic effect on PAH formation in counterflow diffusion flames, Combust. Flame $160 \quad$ (2013) 1667-1676. https://doi.org/10.1016/j.combustflame.2013.03.013.

[71] A. Kempf, M. Klein, J. Janicka, Efficient Generation of Initial- and Inflow-Conditions for Transient Turbulent Flows in Arbitrary Geometries, Flow, Turbulence and Combustion 74 (2005) 67-84. 